\title{
Regional prioritisation of flood risk in mountainous areas
}

\author{
María Carolina Rogelis ${ }^{1}$, Micha Werner ${ }^{1,2}$, Nelson Obregón ${ }^{3}$, and Nigel Wright ${ }^{4}$ \\ ${ }^{1}$ UNESCO-IHE, P.O. Box 3015, 2601DA Delft, the Netherlands \\ ${ }^{2}$ Deltares, P.O. Box 177, 2600MH Delft, the Netherlands \\ ${ }^{3}$ Universidad Javeriana, KR 7 No 40-62, Bogotá, Colombia \\ ${ }^{4}$ School of Civil Engineering, University of Leeds, Leeds, LS2 9JT, UK \\ Correspondence to: María Carolina Rogelis (c.rogelisprada@unesco-ihe.org) \\ Received: 13 May 2015 - Published in Nat. Hazards Earth Syst. Sci. Discuss.: 2 July 2015 \\ Revised: 19 January 2016 - Accepted: 16 February 2016 - Published: 23 March 2016
}

\begin{abstract}
In this paper a method is proposed to identify mountainous watersheds with the highest flood risk at the regional level. Through this, the watersheds to be subjected to more detailed risk studies can be prioritised in order to establish appropriate flood risk management strategies. The prioritisation is carried out through an index composed of a qualitative indicator of vulnerability and a qualitative flash flood/debris flow susceptibility indicator. At the regional level, vulnerability was assessed on the basis of a principal component analysis carried out with variables recognised in literature to contribute to vulnerability, using watersheds as the unit of analysis. The area exposed was obtained from a simplified flood extent analysis at the regional level, which provided a mask where vulnerability variables were extracted. The vulnerability indicator obtained from the principal component analysis was combined with an existing susceptibility indicator, thus providing an index that allows the watersheds to be prioritised in support of flood risk management at regional level. Results show that the components of vulnerability can be expressed in terms of three constituent indicators: (i) socio-economic fragility, which is composed of demography and lack of well-being; (ii) lack of resilience and coping capacity, which is composed of lack of education, lack of preparedness and response capacity, lack of rescue capacity, cohesiveness of the community; and (iii) physical exposure, which is composed of exposed infrastructure and exposed population. A sensitivity analysis shows that the classification of vulnerability is robust for watersheds with low and high values of the vulnerability indicator, while some watersheds with intermediate values of the indicator are sensitive to shifting between medium and high vulnerability.
\end{abstract}

\section{Introduction}

Flood risk represents the probability of negative consequences due to floods and emerges from the convolution of flood hazard and flood vulnerability (Schanze et al., 2006). Assessing flood risk can be carried out at national, regional or local level (IWR, 2011), with the regional scale aiming to contribute to regional flood risk management policy and planning. Approaches used to assess flood risk vary widely. These include the assessment of hazard using model-based hazard analyses and combining these with damage estimations to derive a representation of risk (Liu et al., 2014; Su and Kang, 2005), as well as indicator-based analyses that focus on the assessment of vulnerability through composite indices (Chen et al., 2014; Safaripour et al., 2012; Greiving, 2006). The resulting levels of risk obtained may subsequently be used to obtain grades of the risk categories (e.g. high, medium and low) that allow prioritisation, or ranking of areas for implementation of flood risk reduction measures, such as flood warning systems and guiding preparations for disaster prevention and response (Chen et al., 2014).

A risk analysis consists of an assessment of the hazard as well as an analysis of the elements at risk. These two aspects are linked via damage functions or loss models, which quantitatively describe how hazard characteristics affect specific elements at risk. This kind of damage or loss modelling typically provides an estimate of the expected monetary loss (Seifert et al., 2009; Luna et al., 2014; van Westen et al., 2014; Mazzorana et al., 2012). However, more holistic approaches go further, incorporating social, economic, cultural, institutional and educational aspects, and their interdependence (Fuchs, 2009). In most cases these are the underly- 
ing causes of the potential physical damage (Cardona, 2003; Cardona et al., 2012; Birkmann et al., 2014). A holistic approach provides crucial information that supplements flood risk assessments, informing decision makers on the particular causes of significant loss from a given vulnerable group and providing tools to improve the social capacities of flood victims (Nkwunonwo et al., 2015). The need to include social, economic and environmental factors, as well as physical factors in vulnerability assessments, is incorporated in the Hyogo Framework for Action and emphasised in the Sendai Framework for Disaster Risk Reduction 2015-2030, which establishes the need to understand disaster risks in all its dimensions as a priority (United Nations General Assembly, 2015). However, the multi-dimensional nature of vulnerability has been addressed by few studies (Papathoma-Köhle et al., 2011).

The quantification of the physical dimension of vulnerability can be carried out through empirical and analytical methods (Sterlacchini et al., 2014). However, when the multiple dimensions of vulnerability are taken into account, challenges arise in the measurement of aspects of vulnerability that can not be easily quantified. Birkmann (2006) suggests that indicators and indices can be used to measure vulnerability from a comprehensive and multidisciplinary perspective, capturing both direct physical impacts (exposure and susceptibility), and indirect impacts (socio-economic fragility and lack of resilience). The importance of indicators is rooted in their potential use for risk management since they are useful tools for (i) identifying and monitoring vulnerability over time and space, (ii) developing an improved understanding of the processes underlying vulnerability, (iii) developing and prioritising strategies to reduce vulnerability and for (iv) determining the effectiveness of those strategies (Rygel et al., 2006). However, developing, testing and implementing indicators to capture the complexity of vulnerability remains a challenge.

The use of indices for vulnerability assessment has been adopted by several authors, for example, Balica et al. (2012) describe the use of a Flood Vulnerability Index , an indicatorbased methodology that aims to identify hotspots related to flood events in different regions of the world. Müller et al. (2011) used indicators derived from geodata and census data to analyse the vulnerability to floods in a dense urban setting in Chile. A similar approach was followed by Barroca et al. (2006), organising the choice of vulnerability indicators and the integration from the point of view of various stakeholders into a software tool. Cutter et al. (2003) constructed an index of social vulnerability to environmental hazards at county level for the United States. However, several aspects of the development of these indicators continue to demand research efforts, including the selection of appropriate variables that are capable of representing the sources of vulnerability in the specific study area, the determination of the importance of each indicator, the availability of data to analyse and assess the indicators, the limitations in the scale of the analysis (geographic unit and time frame) and the validation of the results (Müller et al., 2011). Since no variable has yet been identified against which to fully validate vulnerability indicators, an alternative approach to assess the robustness of indices is to identify the sensitivity of how changes in the construction of the index may lead to changes in the outcome (Schmidtlein et al., 2008).

Vulnerability is closely tied to natural and man-made environmental degradation at urban and rural levels (Cardona, 2003; UNEP, 2003). At the same time the intensity or recurrence of flood hazard events can be partly determined by environmental degradation and human intervention in natural ecosystems (Cardona et al., 2012). This implies that human actions on the environment determine the construction of risk, influencing the exposure and vulnerability as well as enhancing or reducing hazard. For example, the construction of a bridge can increase flood hazard upstream by narrowing the width of the channel, increasing the resistance to flow and therefore resulting in higher water levels that may inundate a larger area upstream.

The interaction between flood hazard and vulnerability is explored in small watersheds in a mountainous environment, where human-environment interactions that influence risk levels take place in a limited area. The hydrological response of these watersheds is sensitive to anthropogenic interventions, such as land use change (Seethapathi et al., 2008).

The consequence of the interaction between hazard and vulnerability in such small watersheds is that those at risk of flooding play a crucial role themselves in the processes that enhance hazard, through modification of the natural environment. Unplanned urbanisation, characterised by a lack of adequate infrastructure and socio-economic issues (both contributors to vulnerability) may also result in environmental degradation, which increases the intensity of natural hazards (UNISDR, 2004). In the case of floods, such environmental degradation may lead to an increase in peak discharges, flood frequency and sediment load.

In this paper a method is proposed to identify montane watersheds with the highest flood damage potential at the regional level. Through this, the watersheds to be subjected to more detailed risk studies can be prioritised in order to establish appropriate flood risk management strategies. The method is demonstrated in the montane watersheds that surround the city of Bogotá (Colombia), where floods typically occur as flash floods and debris flows.

The prioritisation is carried out through an index composed of a qualitative indicator of vulnerability and a qualitative indicator of the susceptibility of the watersheds to the occurrence of flash floods/debris flows. Vulnerability is assessed through application of an indicator system that considers social, economic and physical aspects that are derived from the available data in the study area. This is subsequently combined with an indicator of flash flood/debris flow susceptibility that is based on morphometry and land cover, and was applied to the same area in a previous study (Rogelis 
and Werner, 2013). In the context of the flash flood/debris flow susceptibility indicator, susceptibility is considered as the spatial component of the hazard assessment, showing the different likelihoods that flash floods and debris flow occur in the watersheds. In contrast, risk is defined as the combination of the probability of an event and its negative consequences (UNISDR, 2009). The priority index can be considered a proxy for risk, identifying potential for negative consequences but not including probability estimations.

The paper is structured as follows: (i) Sect. 2 reviews the conceptual definition of vulnerability as the foundation of the paper; (ii) Sect. 3 describes the study area, and the data and methodology used; (iii) Sect. 4 presents the results of the analysis; this includes the construction of the indicators and the corresponding sensitivity analysis, as well as the prioritisation of watersheds; (iv) Sect. 5 interprets the results that lead to the final prioritisation; (v) the conclusions are summarised in Sect. 6.

\section{Conceptualisation of vulnerability}

Several concepts of vulnerability can be identified, and there is not a universal definition of this term (Thieken et al., 2006; Birkmann, 2006). Birkmann (2006) distinguishes at least six different schools of thinking regarding the conceptual and analytical frameworks on how to systematise vulnerability. In these, the concept of exposure and its relation with vulnerability, the inclusion of the coping capacity as part of vulnerability and the differentiation between hazard-dependent and hazard-independent characteristics of vulnerability play an important role. Sterlacchini et al. (2014) identifies at least two different perspectives: (i) one related to an engineering and natural science overview; and (ii) a second one related to a social science approach.

With relation to the first perspective (i), vulnerability is defined as the expected degree of loss for an element at risk, occurring due to the impact of a defined hazardous event (Varnes, 1984; Fuchs, 2009; Holub et al., 2012). The relationship between impact intensity and degree of loss is commonly expressed in terms of a vulnerability curve or vulnerability function (Totschnig and Fuchs, 2013), although also semi-quantitative and qualitative methods exist (Totschnig and Fuchs, 2013; Fuchs et al., 2007; Jakob et al., 2012; Kappes et al., 2012). The intensity criteria of torrent (steep stream) processes, encompassing clear water, hyperconcentrated and debris flows, has been considered in terms of impact forces (Holub et al., 2012; Quan Luna et al., 2011; Hu et al., 2012); deposit height (Mazzorana et al., 2012; Fuchs et al., 2012, 2007; Akbas et al., 2009; Totschnig et al., 2011; Lo et al., 2012; Papathoma-Köhle et al., 2012; Totschnig and Fuchs, 2013); kinematic viscosity (Quan Luna et al., 2011; Totschnig et al., 2011); flow depth (Jakob et al., 2013; Tsao et al., 2010; Totschnig and Fuchs, 2013); flow velocity times flow depth (Totschnig and Fuchs, 2013); and velocity squared times flow depth (Jakob et al., 2012). Dif- ferent types of elements at risk will show different levels of damage given the same intensity of hazard (Jha et al., 2012; Albano et al., 2014; Liu et al., 2014), therefore vulnerability curves are developed for a particular type of exposed element (such as construction type, building dimensions or road access conditions). A limited number of vulnerability curves for torrent processes have been proposed, and the efforts have been mainly oriented to residential buildings (Totschnig and Fuchs, 2013). Since it can be difficult to extrapolate data gathered from place to place to different building types and contents (Papathoma-Köhle et al., 2011), different curves should be created for different geographical areas and then applied to limited and relatively homogeneous regions (Luino et al., 2009; Jonkman et al., 2008; Fuchs et al., 2007).

Regarding the second perspective (ii), social sciences define vulnerability as the pre-event, inherent characteristics or qualities of social systems that create the potential for harm (Cutter et al., 2008). This definition is focused on the characteristics of a person or group and their situation that influence their capacity to anticipate, cope with, resist and recover from the impact of a hazard (Wisner et al., 2003). Social and place inequalities are recognised as influencing vulnerability (Cutter et al., 2003). The term livelihood is highlighted and used to develop models of access to resources, like money, information, cultural inheritance or social networks, influencing people's vulnerability (Hufschmidt et al., 2005).

Given the different perspectives of vulnerability, it becomes apparent that only by a multidimensional approach can the overall aim of reducing natural hazards risk be achieved (Fuchs and Holub, 2012). Fuchs (2009) identifies a structural (physical) dimension of vulnerability that is complemented by economic, institutional and societal dimensions. In addition to these, Sterlacchini et al. (2014) identify a political dimension. Birkmann et al. (2014) and Birkmann et al. (2013) identify exposure, fragility and lack of resilience as key causal factors of vulnerability, as well as physical, social, ecological, economic, cultural and institutional dimensions.

In this study, physical exposure (hard risk and considered to be hazard-dependent), socioeconomic fragility (soft risk and considered to be not hazard-dependent) and lack of resilience and coping capacity (soft risk and is mainly not hazard-dependent) (Cardona, 2001) are used to group the variables that determine vulnerability in the study area. In this paper, the risk perception and the existence of a flood early warning, which are hazard-dependent, are considered as aspects influencing resilience since they influence the hazard knowledge of the communities at risk and the level of organisation to cope with floods. An analysis of physical vulnerability through vulnerability curves is not incorporated; instead, the expected degree of loss is assessed qualitatively through the consideration of physical exposure and factors that amplify the loss (socioeconomic fragility and lack of resilience). This means the expected degree of loss depends on 
the extent of the flash floods/debris flows, and not on the intensity of those events.

The terminology and definitions that are used in this study are as follows:

- vulnerability: propensity of exposed elements such as physical or capital assets, as well as human beings and their livelihoods, to experience harm and suffer damage and loss when impacted by a single or compound hazard events (Birkmann et al., 2014);

- exposure: people, property, systems or other elements present in hazard zones that are thereby subject to potential loss (UNISDR, 2009);

- fragility: predisposition of elements at risk to suffer harm (Birkmann et al., 2014);

- lack of resilience and coping capacity: limited capacities to cope or to recover in the face of adverse consequences (Birkmann et al., 2014).

\section{Methods and data}

\subsection{Study area}

Bogotá is the capital city of Colombia with 7 million inhabitants and an urban area of approximately $385 \mathrm{~km}^{2}$. The city is located on a plateau at an elevation of $2640 \mathrm{~m}$ a.s.l. and is surrounded by mountains from where several creeks drain to the Tunjuelo, Fucha and Juan Amarillo rivers. These rivers flow towards the Bogotá River. Precipitation in the city is characterised by a bimodal regime with mean annual precipitation ranging from 600 to $1200 \mathrm{~mm}$ (Bernal et al., 2007).

Despite its economic output and growing character as a global city, Bogotá suffers from social and economic inequalities, lack of affordable housing and overcrowding. Statistics indicate that there has been a significant growth in the population, which also demonstrates the process of urban immigration that the whole country is suffering not only due to industrialisation processes, but also due to violence and poverty. This disorganised urbanisation process has pushed informal settlers to build their homes in highly unstable zones and areas that can be subjected to inundation. Eighteen percent of the urban area has been occupied by informal constructions, housing almost 1400000 persons. This is some $22 \%$ of the urban population of Bogotá (Pacific Disaster Center, 2006).

Between 1951 and 1982, the lower (northern) part of the Tunjuelo Basin (see Fig. 1) was the most important area for urban development in the city, where the poorest population of Bogotá were settled (Osorio, 2007). This growth has been characterised by informality and lack of planning. This change in the land use caused loss of vegetation and erosion, which enhanced flood hazard (Osorio, 2007).
The urban development of the watersheds located in the hills to the east of Bogotá (see Fig. 1) has a different characteristic to that of the Tunjuelo Basin. Not only has this taken place through both informal settlements, but also includes exclusive residential developments (Buendía, 2013). In addition, protected forests cover most of the upper watersheds.

In this analysis the watersheds located in mountainous terrain that drain into the main stream of the Tunjuelo Basin, as well as the watersheds in the Eastern Hills, were considered. The remaining part of the urban area of the city covers an area that is predominantly flat, and is not considered in this study. Table 1 shows the number of watersheds in the study area, as well as the most recent and severe flood events that have been recorded.

\subsection{Methodology}

The prioritisation of flood risk was carried out using watersheds in the study area as units of analysis. The watershed divides were delineated up to the confluence with the Tunjuelo River, or up to the confluence with the storm water system, whichever is applicable. First a delineation of areas exposed to flooding from these watersheds using simplified approaches was carried out. Subsequently a vulnerability indicator was constructed based on a principal component analysis of variables identified in the literature as contributing to vulnerability. A sensitivity analysis was undertaken to test the robustness of the vulnerability indicator. From the vulnerability indicator, a category (high, medium and low vulnerability) was obtained that was then combined with a categorisation of flash flood/debris flow susceptibility previously generated in the study area to obtain a prioritisation category. The tool that was used to combine vulnerability and susceptibility was a matrix that relates the susceptibility levels and vulnerability levels producing a priority level as output. The combination matrix was constructed through the assessment of all possible matrices using as assessment criterion the "proportion correct". In order to obtain the proportion correct an independent classification of the watersheds was carried out on the basis of the existing damage data.

A detailed explanation of the analysis is given in the following subsections.

\subsubsection{Delineation of exposure areas}

Flood events in the watersheds considered in this study typically occur as flash floods given their size and mountainous nature. Flash floods in such small, steep watersheds can further be conceptualised to occur as debris flows, hyperconcentrated flows or clear water flows (Hyndman and Hyndman, 2008; Jakob et al., 2004; Costa, 1988). Costa (1988) differentiates (i) clear water floods as Newtonian, turbulent fluids with non-uniform concentration profiles and sediment concentrations of less than about $20 \%$ by volume and shear strengths less than $10 \mathrm{~N} \mathrm{~m}^{-2}$; (ii) hyperconcentrated flows 

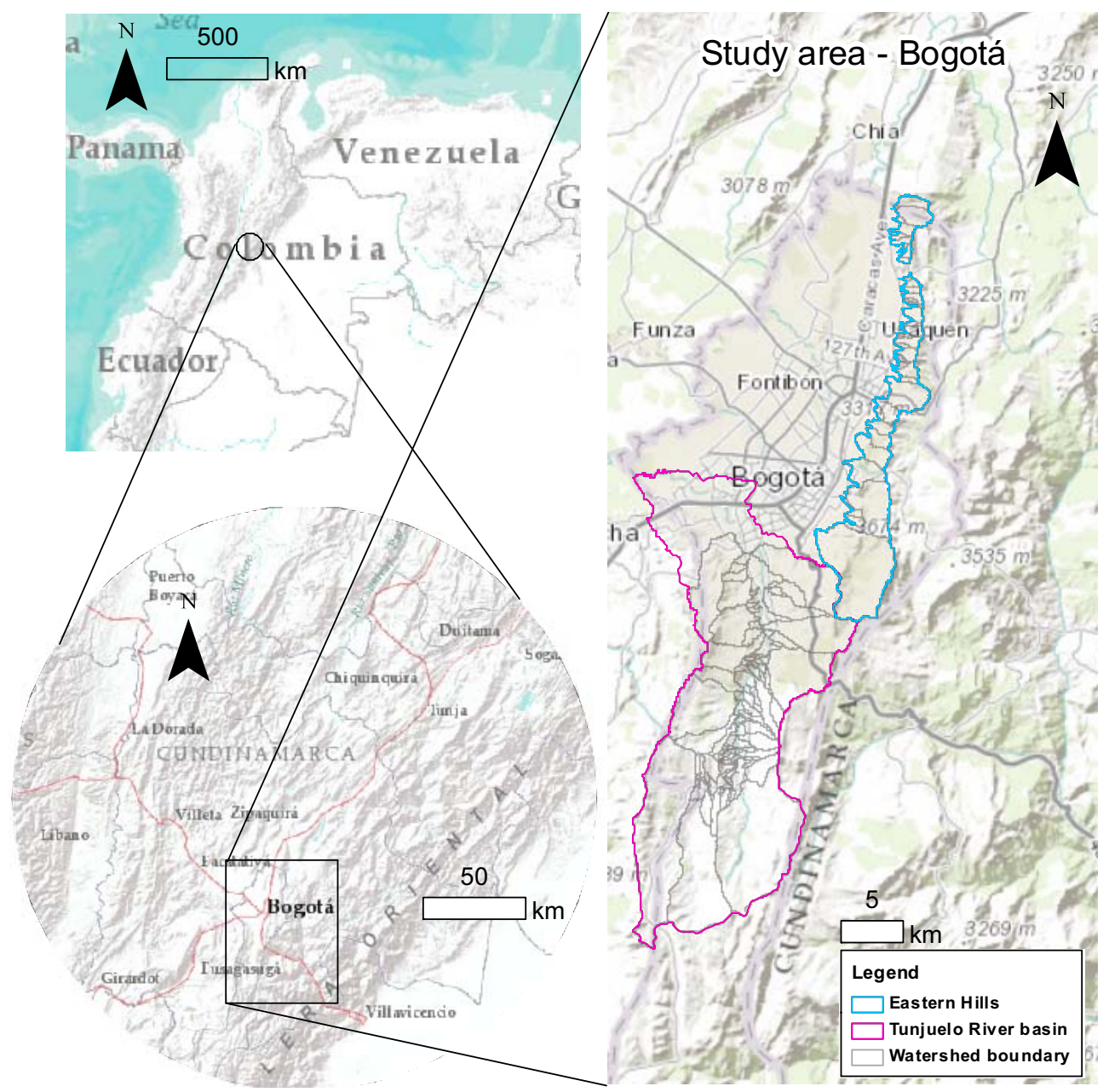

Figure 1. Location of the study areas.

Table 1. Most severe recent flooding events in the study area

\begin{tabular}{|c|c|c|c|c|}
\hline \multicolumn{5}{|r|}{ Watersheds } \\
\hline Study area & Number & $\begin{array}{l}\text { Average } \\
\text { slope } \\
(\%)\end{array}$ & $\begin{array}{l}\text { Area } \\
\left(\mathrm{km}^{2}\right)\end{array}$ & Recent flooding events \\
\hline $\begin{array}{l}\text { Tunjuelo River } \\
\text { basin }\end{array}$ & 66 & $12-40$ & $0.2-57$ & $\begin{array}{l}\text { The most severe events include the following. } \\
\text { - In May 1994, a debris flow affected } 830 \text { people and caused the } \\
\text { death of four people in the north-east of the basin (JICA, 2006). } \\
\text { - In November 2003, a hyperconcentrated flow took place in the } \\
\text { north-west of the Tunjuelo Basin. Two people were killed and } \\
1535 \text { were affected. A similar event occurred at the same location } \\
\text { in November } 2004 \text { without a death toll (DPAE, 2003a, b). }\end{array}$ \\
\hline
\end{tabular}

\begin{tabular}{lllll}
\hline Eastern Hills & 40 & $21-59$ & $0.2-33$ & The most severe events include the following.
\end{tabular}

- In May 2005, a hyperconcentrated flow occurred in the central part of the area, affecting two houses (DPAE, 2005). 
as having sediment concentrations ranging from 20 to $47 \%$ by volume and shear strengths lower than about $40 \mathrm{~N} \mathrm{~m}^{-2}$; and (iii) debris flows as being non-Newtonian visco-plastic or dilatant fluids with laminar flow and uniform concentration profiles, with sediment concentrations ranging from 47 to $77 \%$ by volume and shear strengths greater than about $40 \mathrm{~N} \mathrm{~m}^{-2}$. Debris-flow-dominated areas can be subject to hyperconcentrated flows as well as clear water floods (Larsen et al., 2001; Santo et al., 2015; Lavigne and Suwa, 2004), depending on the hydroclimatic conditions and the availability of sediments (Jakob, 2005); occurrence of all types in the same watersheds has been reported (Larsen et al., 2001; Santo et al., 2015). Therefore, the areas exposed to clear water floods and debris flows were combined. This provides a conservative delineation of the areas considered to be exposed to flooding.

Exposure areas were obtained from an analysis of the susceptibility to flooding. Areas that can potentially be affected by clear water floods and debris flows were determined using simplified methods that provide a mask where the analysis of exposed elements was carried out. The probabilities of occurrence and magnitude are not considered in the analysis, since the scope of the simplified regional assessment is limited to assessing the susceptibility of the watersheds to flooding. Areas prone to debris flows were previously identified by Rogelis and Werner (2013) through application of the Modified Single-Flow Direction model.

In order to delineate the areas prone to clear water floods, or floodplains, two geomorphic-based methods were tested using a digital elevation model with a pixel size of $5 \mathrm{~m}$ as an input, which was obtained from contours. Floodplains are areas near stream channels shaped by the accumulated effects of floods of varying magnitudes and their associated geomorphological processes. These areas are also referred to as valley bottoms and riparian areas or buffers (Nardi et al., 2006).

The first approach is the multi-resolution valley bottom flatness (MRVBF) algorithm (Gallant and Dowling, 2003). The MRVBF algorithm identifies valley bottoms using a slope classification constrained on convergent area. The classification algorithm is applied at multiple scales by progressive generalisation of the digital elevation model, combined with progressive reduction of the slope class threshold. The results at different scales are then combined into a single index. The MRVBF index utilises the flatness and lowness characteristics of valley bottoms. Flatness is measured by the inverse of slope, and lowness is measured by ranking the elevation with respect to the surrounding area. The two measures, both scaled to the range 0 to 1 , are combined by multiplication and could be interpreted as membership functions of fuzzy sets. While the MRVBF is a continuous measure, it naturally divides into classes corresponding to the different resolutions and slope thresholds (Gallant and Dowling, 2003).
In the second method considered, threshold buffers are used to delineate floodplains as areas contiguous to the streams based on height above the stream level. Cells in the digital elevation model adjacent to the streams that meet height thresholds are included in the buffers (Cimmery, 2010). Thresholds for the height of 1, 2, 3, 4, 5, 7 and $10 \mathrm{~m}$ were tested.

In order to evaluate the results of the MRVBF index and the threshold buffers, flood maps for the study area were used. These are available for only 9 of the 106 watersheds, and were developed in previous studies through hydraulic modelling for return periods up to 100 years. The delineation of the flooded area for a return period of 100 years was used in the nine watersheds to identify the suitability of the floodplain delineation methods to be used in the whole study area. With respect to areas prone to debris flows, these were validated with existing records in the study area by Rogelis and Werner (2013).

\subsubsection{Choice of indicators and principal component analysis for vulnerability assessment}

In this study vulnerability in the areas identified as being exposed is assessed through the use of indicators. The complexity of vulnerability requires a transformation of available data to a set of important indicators that facilitate an estimation of vulnerability (Birkmann, 2006). To this end, principal component analysis was applied to variables describing vulnerability in the study area in order to create composite indicators (Cutter et al., 2003). The variables were chosen by taking into account their usefulness according to the literature, and were calculated using the exposure areas as a mask.

Table 2 shows the variables chosen to explain vulnerability in the study area. These are grouped in socio-economic fragility, lack of resilience and coping capacity and physical exposure. The variables are classified according to their social level (individual, household, community and institutional), hazard dependence and influence on vulnerability (increase or decrease). The third column specifies the spatial aggregation level of the available data. The three spatial levels considered are urban block, watershed and locality, where the locality corresponds to the 20 administrative units of the city. The data used to construct the indicators were obtained from the census and reports published by the municipality. For each variable the values were normalised between the minimum and the maximum found in the study area. In the case of variables that contribute to decreasing vulnerability, a transformation was applied so a high variable value represents high vulnerability for all variables.

In order to construct the composite indicators related to socio-economic fragility and physical exposure, principal component analysis (PCA) was applied to the corresponding variables shown in Table 2. PCA reduces the dimensionality of a data set consisting of a large number of interrelated variables, while retaining as much as possible of the varia- 
Table 2. Variables used to construct vulnerability indicators.

\begin{tabular}{|c|c|c|c|c|}
\hline Social levels & Variable & \begin{tabular}{|l|l}
\multirow{y}{*}{} & \\
\\
\end{tabular} & Spatial level & Description \\
\hline \multicolumn{5}{|c|}{ Socio-economic fragility } \\
\hline \multirow{7}{*}{ Individual } & Age & & Urban block & Percentage $<10$ plus percentage $>65$ \\
\hline & Disability & & Urban block & $\%$ of population with any sort of disability \\
\hline & Unemployment & & Locality & Unemployment rate \\
\hline & Income & & Locality & $\begin{array}{l}\text { Unsatisfied basic needs index - UBN, \% of homeless, \% of poor } \\
\text { population }\end{array}$ \\
\hline & Life expectancy & & Locality & Life expectancy \\
\hline & Household size & & Locality & Average number of persons per household \\
\hline & $\begin{array}{l}\text { Woman-headed } \\
\text { households }\end{array}$ & & Locality & Percentage of families headed by women \\
\hline \multirow{6}{*}{ Community } & Illegal settlements & & Urban block & Percentage of illegal settlements \\
\hline & $\begin{array}{l}\% \text { of population } \\
\text { of strata } 1 \text { and } 2\end{array}$ & & Urban block & $\begin{array}{l}\text { The socio-economic stratification system of Bogotá classifies } \\
\text { the population into strata with similar economic } \\
\text { characteristics on a scale from } 1 \text { to } 6 \text {, with } 1 \text { as the lowest } \\
\text { income area and } 6 \text { as the highest. Strata } 1 \text { and } 2 \text { correspond } \\
\text { to the socio-economic classification with the lowest income. }\end{array}$ \\
\hline & Life conditions & & Locality & Life conditions index \\
\hline & $\begin{array}{c}\text { Human } \\
\text { development index }\end{array}$ & & Locality & Human development index \\
\hline & $\begin{array}{l}\text { Demographic } \\
\text { pressure }\end{array}$ & & Locality & Population growth rate \\
\hline & Child mortality & & Locality & Child mortality rate \\
\hline Institutional & --- & --- & --- & --- \\
\hline \multicolumn{5}{|c|}{ Lack of resilience and coping capacity } \\
\hline \multirow{3}{*}{ Individual } & Level of education & & Locality & $\%$ of population with education level superior to high school \\
\hline & Illiteracy & & Locality & Illiteracy rate \\
\hline & Access to information & & Locality & $\%$ of homes with internet access \\
\hline Household & -- & --- & -- & -- \\
\hline \multirow{3}{*}{ Community } & Risk perception & & Watershed & $\begin{array}{l}\text { Boolean indicator. A value of } 1 \text { was assigned to watersheds } \\
\text { where floods have occurred previously and } 0 \text { if } \\
\text { they have not. }\end{array}$ \\
\hline & Robberies & & Locality & $\begin{array}{l}\text { Robberies per } 10000 \text { inhabitants. The robberies that } \\
\text { occur in the locality of the watershed were used as a proxy for } \\
\text { trust, confidence and the level at which a proper post-disaster } \\
\text { environment could be expected, since a high probability of } \\
\text { crime can affect the evacuation procedures and the process to } \\
\text { recover. }\end{array}$ \\
\hline & Participation & & Locality & $\begin{array}{l}\text { Percentage of eligible voters that voted in the most } \\
\text { recent communal elections. }\end{array}$ \\
\hline \multirow{5}{*}{ Institutional } & $\begin{array}{l}\text { Infrastructure/ } \\
\text { accessibility }\end{array}$ & & Locality & $\%$ of roads in good condition \\
\hline & Early warning & & Watershed & $\begin{array}{l}\text { Boolean indicator. Existence of flood early warning systems in } \\
\text { the watershed. Watersheds where flood early warning systems } \\
\text { are operational were assigned a value of } 1 \text { and } 0 \text { if they do not } \\
\text { exist. }\end{array}$ \\
\hline & Hospital beds & & Locality & Hospital beds per 10000 inhabitants \\
\hline & Healthcare HR & & Locality & Healthcare human resources per 10000 inhabitants \\
\hline & Rescue personnel & & Locality & Rescue personnel per 10000 inhabitants. \\
\hline \multicolumn{5}{|c|}{ Physical exposure } \\
\hline \multirow{2}{*}{ Individual } & Population exposed & & Urban block & Number of people in flood-prone areas \\
\hline & Density of population & & Urban block & People per $\mathrm{km}^{2}$ in flood-prone areas. \\
\hline Household & Residential units & & Urban block & Number of houses in flood-prone area \\
\hline \multirow{2}{*}{ Community } & $\begin{array}{l}\text { Commercial and } \\
\text { industrial units }\end{array}$ & & Urban block & $\begin{array}{l}\text { Number of commercial and industrial establishments in flood- } \\
\text { prone area. }\end{array}$ \\
\hline & $\begin{array}{l}\text { Community } \\
\text { infrastructure }\end{array}$ & & Urban block & $\begin{array}{l}\text { Number of community, social, cultural, healthcare } \\
\text { infrastructure exposed }\end{array}$ \\
\hline Institutional & -- & --- & --- & --- \\
\hline \multirow[t]{3}{*}{ Legend: } & \multicolumn{3}{|l|}{ Variable } & Effect \\
\hline & \multicolumn{3}{|c|}{ Hazard-dependent } & Increases vulnerability \\
\hline & \multicolumn{3}{|c|}{ Hazard-independent } & Reduces vulnerability \\
\hline
\end{tabular}

tion present in the data set. This is achieved by transforming to a new set of variables, the principal components (PCs), which are uncorrelated (Jolliffe, 2002). The number of com- ponents to be retained from the PCA was chosen by considering four criteria: the Scree test acceleration factor, optimal coordinates (Cattell, 1966), the Kaiser's eigenvalue-greater- 
than-one rule (Kaiser, 1960) and parallel analysis (Horn, 1965). Since the number of components may vary among these criteria, the interpretability was also taken into account when selecting the components to be used in further analysis, with each PC being considered an intermediate indicator. Subsequently a varimax rotation (Kaiser, 1958) was applied to minimise the number of individual indicators that have a high loading on the same principal component, thus obtaining a simpler structure with a clear pattern of loadings (Nardo et al., 2008). The intermediate indicators (PCs) were aggregated using a weight equal to the proportion of the explained variance in the data set (Nardo et al., 2008) to provide an overall indicator for socio-economic fragility and for physical exposure.

PCA has the disadvantage that correlations do not necessarily represent the real influence of the individual indicators and variables on the phenomenon being measured (Nardo et al., 2008). This can be addressed by combining PCA weights with an equal weighing scheme for those variables where PCA does not lead to interpretable results (Esty et al., 2006). In the construction of the lack of resilience and coping capacity indicator, this issue led to a separation of variables into four groups.

- Robberies and participation: these were treated separately from the rest of the variables to maintain interpretability as a measure of cohesiveness of the community. Cohesiveness of the community was identified as a factor that influences the resilience since the degradation of social networks limits the social organisation for emergency response (Ruiz-Pérez and Gelabert Grimalt, 2012). Since there are only two variables to measure this aspect of resilience, PCA was not applied, and the average of the variables was used instead.

- Risk perception and early warning: risk perception depends on the occurrence of previous floods, thus it depends on hazard exclusively. The existence of early warning is mainly an institutional and organisational issue. Therefore, an interpretation of correlation of these variables with other variables in the group of lack of resilience and coping capacity is not possible. These variables were considered separated intermediate indicators. Risk perception and early warning decrease the lack of coping capacity (Molinari et al., 2013), and therefore an equal negative weight was assigned to these indicators, with a total of -0.2 . This value was chosen so that their combined influence is less than the individual weight of the other four indicators. The sensitivity of this subjective choice was tested. The effectiveness of flood early warning is closely related to the level of preparedness as well as the available time for implementation of appropriate actions (Molinari et al., 2013). Due to the rapid hydrologic response and configuration of the watersheds in the study area, flood early warning actions are targeted at reducing exposure and vulnerability and not at hazard reduction.

- Rescue personnel: this variable was initially used in the PCA with all lack of resilience and coping capacity variables. However, it was found to increase with lack of resilience and coping capacity. This implied that the statistical behaviour of the variable did not represent its real influence on vulnerability. It was therefore treated independently.

- Level of education, illiteracy, access to information, infrastructure/accessibility, hospital beds and healthcare human resources (HR): PCA was applied to these variables, since they exhibit high correlation and are interpretable in terms of their influence on vulnerability.

To combine all the lack of resilience and coping capacity intermediate indicators into a composite indicator, weights with a total of 1 were assigned (see Sect. 4.3 for an explanation of the resulting intermediate indicators).

The indicators corresponding to socio-economic fragility, lack of resilience and coping capacity and physical exposure were combined, assigning equal weight to the three components, to obtain an overall vulnerability indicator. The watersheds were subsequently categorised as being low, medium or high vulnerability based on the value of the vulnerability indicator and using equal intervals. This method of categorisation was chosen to avoid dependence on the distribution of the data, so monitoring of evolution in time of vulnerability can be carried out applying the same criteria.

\subsubsection{Sensitivity of the vulnerability indicator}

The influence of all subjective choices applied in the construction of the indicators was analysed. This included both choices made in the application of PCA, and for the weighting scheme adopted for the factors contributing to resilience and total vulnerability.

1. For the application of PCA, sensitivity to the following choices was explored.

a. Four alternatives for the number of components to be retained were assessed as explained in Sect. 3.2.2.

b. Five different methods in addition to the varimax rotation were considered: unrotated solution, quartimax rotation (Carroll, 1953; Neuhaus, 1954), promax rotation (Hendrickson and White, 1964), oblimin (Carroll, 1957), simplimax (Kiers, 1994) and cluster (Harris and Kaiser, 1964).

2. For the weighting scheme, the following choices were made. 
Table 3. Categories of recorded damage

\begin{tabular}{|c|c|c|}
\hline Category & Score & Description \\
\hline Low & 0 & No recorded damage in the watershed \\
\hline Low & 1 & $\begin{array}{l}\text { Events that affect one house without causing injuries or } \\
\text { fatalities and without the need of evacuation }\end{array}$ \\
\hline Low & 2 & $\begin{array}{l}\text { Events that affect one house without causing injuries or } \\
\text { fatalities and with the need of evacuation }\end{array}$ \\
\hline Low & 3 & $\begin{array}{l}\text { Events that affect up to five houses without causing in } \\
\text { juries or fatalities, flood depth less than } 0.5 \mathrm{~m} \text { with evac- } \\
\text { uation of families }\end{array}$ \\
\hline Medium & 4 & $\begin{array}{l}\text { Events that affect up to five houses without causing in } \\
\text { juries or fatalities, flood depth higher than } 0.5 \mathrm{~m} \text { with } \\
\text { evacuation of families }\end{array}$ \\
\hline Medium & 5 & $\begin{array}{l}\text { Events that affect up to } 10 \text { houses without causing in } \\
\text { juries or fatalities, with evacuation of families }\end{array}$ \\
\hline Medium & 6 & $\begin{array}{l}\text { Events that affect } 10-20 \text { houses without causing injuries } \\
\text { or fatalities, with evacuation of families, flood depth } \\
\text { less than } 0.5 \mathrm{~m}\end{array}$ \\
\hline High & 7 & $\begin{array}{l}\text { Events that affect } 10-20 \text { houses without causing injuries } \\
\text { or fatalities, with evacuation of families, flood depth } \\
\text { higher than } 0.5 \mathrm{~m}\end{array}$ \\
\hline High & 8 & $\begin{array}{l}\text { Events that affect } 20-50 \text { houses without causing injuries } \\
\text { or fatalities, with evacuation of families and possibility } \\
\text { of structural damage in the houses }\end{array}$ \\
\hline High & 9 & $\begin{array}{l}\text { Events that affect more than } 50 \text { houses without caus- } \\
\text { ing injuries or fatalities, with evacuation of families and } \\
\text { possibility of structural damage in the houses }\end{array}$ \\
\hline High & 10 & Events that cause fatalities or injuries \\
\hline
\end{tabular}

a. The weights used in the four groups of variables that describe lack of resilience and coping capacity were varied by $\pm 10 \%$.

b. The weights used to combine the three indicators that result in the final vulnerability composite indicator were varied by $\pm 10 \%$.

All possible combinations were assessed and the results in terms of the resulting vulnerability category (high, medium and low) were compared in order to identify substantial differences as a result of the choices of subjective options.

\subsubsection{Categories of recorded damage in the study area}

A database of historical flood events compiled by the municipality was used to classify the watersheds in categories, depending on damages recorded in past flood events. For each of these events the database includes date, location, injured people, fatalities, evacuated people, number of affected houses and an indication of whether the flow depth was higher than $0.5 \mathrm{~m}$ or not. Unfortunately, no information on economic loss is available and as the database only covers the period from 2000 to 2012 it is not possible to carry out a frequency analysis. Complete records were only available for 14 watersheds. The event with the highest impact for each watershed was chosen from the records. Subsequently, the 14 watersheds were ordered according to their highest impact event. The criteria to sort the records and to sort the watersheds according to impact from highest to lowest were the following (in order of importance):

1. fatalities

2. injured people

3. evacuated people

4. number of affected houses.

Watersheds with similar or equal impact were grouped, resulting in 11 groups. The groups were again sorted according to damage. A score from 0 to 10 was assigned, where a score of 0 implies that no flood damage has been recorded in the watershed for a flood event, despite the occurrence of flooding, while a score of 10 corresponds to watersheds where fatalities or serious injuries have occurred (see Table 3). The 11 groups were further classified into three categories according to the emergency management organisation that was needed for the response: (i) low: the response was coordinated locally; (ii) medium: centralised coordination is needed for response with deployment of resources of mainly the emergency management agency; (iii) high: centralised coordination is needed with an inter-institutional response. This classification was made under the assumption 


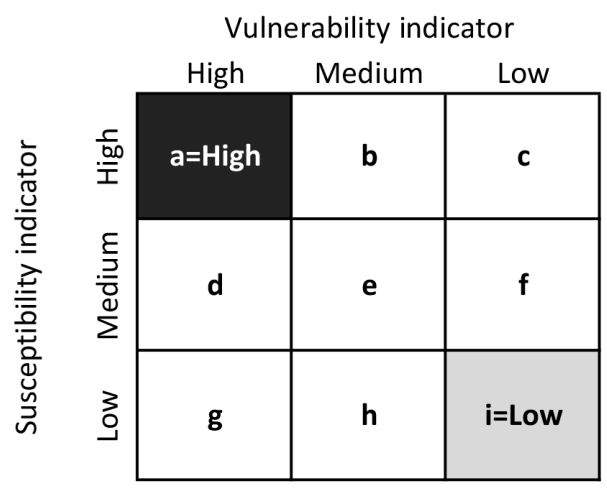

Figure 2. Initial matrix of priority.

that the more resources are needed for response, the more severe the impacts are, allowing in this way a comparison with three levels of priority classification.

\subsubsection{Prioritisation of watersheds}

Due to the regional character and scope of the method applied in this study, a qualitative proxy for risk was used to prioritise the watersheds in the study area. A high priority indicates watersheds where flood events will result in more severe consequences. However, the concept of probability of occurrence of these is not involved in the analysis, since the analysis of flood hazard is limited to susceptibility.

In order to combine the vulnerability and susceptibility to derive a level of risk, a classification matrix was used. This is shown in Fig. 2. The columns indicate the classification of the vulnerability indicator and the rows the classification of the susceptibility indicator. Only two priority outcomes are well defined; these are the high and low degrees assigned to the corners of the matrix corresponding to high susceptibility and high vulnerability and low susceptibility and low vulnerability (cells a and i), since they correspond to the extreme conditions in the analysis. The priority outcomes in cells from $\mathrm{b}$ to $\mathrm{h}$ were considered unknown and to potentially correspond to any category (low, medium or high priority). To define the category for these cells, the priority using all possible matrices (all possible combinations of categories of cells b to c) was assessed for the watersheds for which flood records are available. Once these watersheds are prioritised, a contingency table is constructed comparing the priority with the damage category (from Table 3 ) from which the proportion correct is obtained. The classification matrix that results in the highest proportion correct (best fit) was used for the prioritisation of the whole study area.

\section{Results}

\subsection{Exposure areas}

Figure 4 shows the results of the methods applied to identify areas susceptible to flooding through clear water floods or debris flows. Figure $4 \mathrm{a}$ shows the debris flow propagation extent derived for the watersheds of the Tunjuelo Basin and the Eastern Hills by Rogelis and Werner (2013). Since the method does not take into account the volume that can be deposited on the fan, this shows the maximum potential distance that the debris flow could reach according to the morphology of the area, which is in general flat to the west of the Eastern Hills watersheds. A different behaviour can be observed in the watersheds located in the Tunjuelo River basin where the marked topography and valley configuration restricts the propagation areas.

Figure $4 \mathrm{~b}$ shows the results obtained from the MRVBF index. The comparison of the index with the available flood maps in the study area shows that values of the MRVBF higher than 3 can be considered areas corresponding to valley bottoms. In areas of marked topography the index identifies areas adjacent to the creeks in most cases and the larger scale valley bottoms. However, in flat areas the index unavoidably takes high values and cannot be used to identify flood-prone areas.

Figure $4 \mathrm{c}$ shows the result obtained from the use of buffer thresholds. The buffers that were obtained by applying the criteria explained in Sect. 3.2.1 were compared with the available flood maps. Areas obtained for a depth criterion of $3 \mathrm{~m}$ were the closest to the flood delineation for a return period of 100 years, and this value was chosen as appropriate for the study area.

In order to obtain the delineation of the exposure areas, the results of the debris flow propagation, the MRVBF index and the buffers were combined. The results of all three methods in flat areas do not allow for a correct identification of floodprone areas, and a criterion based on the available information and previous studies was needed to estimate a reasonable area of exposure. The resulting exposure areas are shown in Fig. 5.

\subsection{Socio-economic fragility indicators}

The results of the principal component analysis applying a varimax rotation are shown in Table 4 . Two principal components were retained as this allowed a clear interpretation to be made for each of the components. The variables included in the first principal component are related to lack of well-being $\left(P_{\mathrm{LofW}}\right)$, while in the second these are related to the demography $\left(P_{\text {demog }}\right)$. The two principal components account for $79 \%$ of the variance in the data, with the first component explaining $80 \%$ of the variance (percentage of the variability explained, PVE) and the second $20 \%$. 


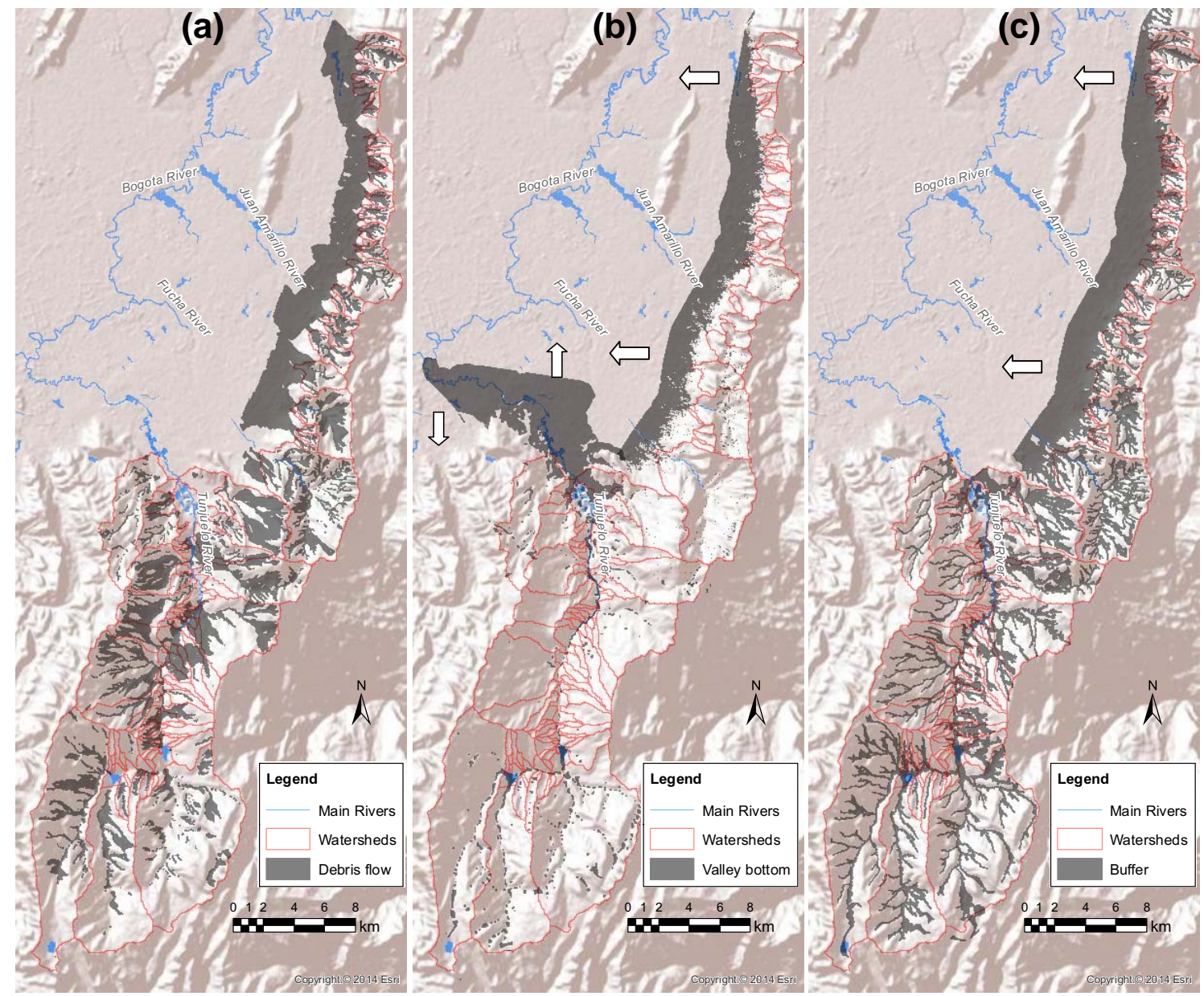

Figure 3. Clear water flood and debris flow susceptibility areas. Areas in dark grey in each map represent; (a) debris flow extent (Rogelis and Werner, 2013); (b) valley bottoms identified using the MRVBF index; (c) buffers. In the case of maps (b) and (c), the flood-prone areas extend in the direction of the arrows over the flat area.

Using the factor loadings (correlation coefficients between the PCs and the variables) obtained from the analysis (see Table 4) and scaling them to unity, the coefficients of each indicator are shown in the following equations:

$$
\begin{aligned}
P_{\mathrm{LofW}}= & 0.10 \mathrm{Whh}+0.10 \mathrm{UE}+0.10 \mathrm{PUBNI}+ \\
& 0.09 \mathrm{Ho}+0.11 \mathrm{P}+0.10 \mathrm{Pho}+0.09 \mathrm{M}+ \\
& 0.10 \mathrm{LE}+0.08 \mathrm{QLI}+0.10 \mathrm{HDI}+0.04 \mathrm{G} \\
P_{\text {demog }}= & 0.32 \mathrm{Age}+0.20 \mathrm{D}+0.29 \mathrm{PE} 12+0.19 \mathrm{IS} .
\end{aligned}
$$

The impacts of the indicators imply that the higher the lack of well-being, the higher the socio-economic fragility, and equally, the higher the demography indicator, the higher the socio-economic fragility. Using the PVE of each component, the composite indicator for socio-economic fragility $\left(P_{\text {soc-ec }}\right)$ is found to be

$P_{\text {soc }- \text { ec }}=0.8 P_{\mathrm{LofW}}+0.2 P_{\mathrm{demog}}$.

\subsection{Lack of resilience and coping capacity indicators}

The loadings of the indicators representing lack of resilience and coping capacity obtained from the PCA are shown in Table 5. Two principal components were used: the first correlated with variables related to the lack of education $\left(P_{\text {LEdu }}\right)$ and the second correlated with variables related to lack of preparedness and response capacity $\left(P_{\text {LPrRCap }}\right)$. These account for $97 \%$ of the variance in the data with the first component explaining $53 \%$ of the variance (PVE) and the second $47 \%$.

Using the factor loadings obtained from the analysis and scaling them to unity, the coefficients of each indicator are shown in the following equations:

$$
\begin{aligned}
& P_{\text {LEdu }}=0.33 \mathrm{LEd}+0.32 \mathrm{I}+0.35 \mathrm{AI} \\
& P_{\text {LPrRCap }}=0.26 \mathrm{IA}+0.39 \mathrm{Hb}+0.35 \mathrm{HRh} .
\end{aligned}
$$

In an initial analysis, the variable rescue personnel was included in the principal component analysis. Results showed 


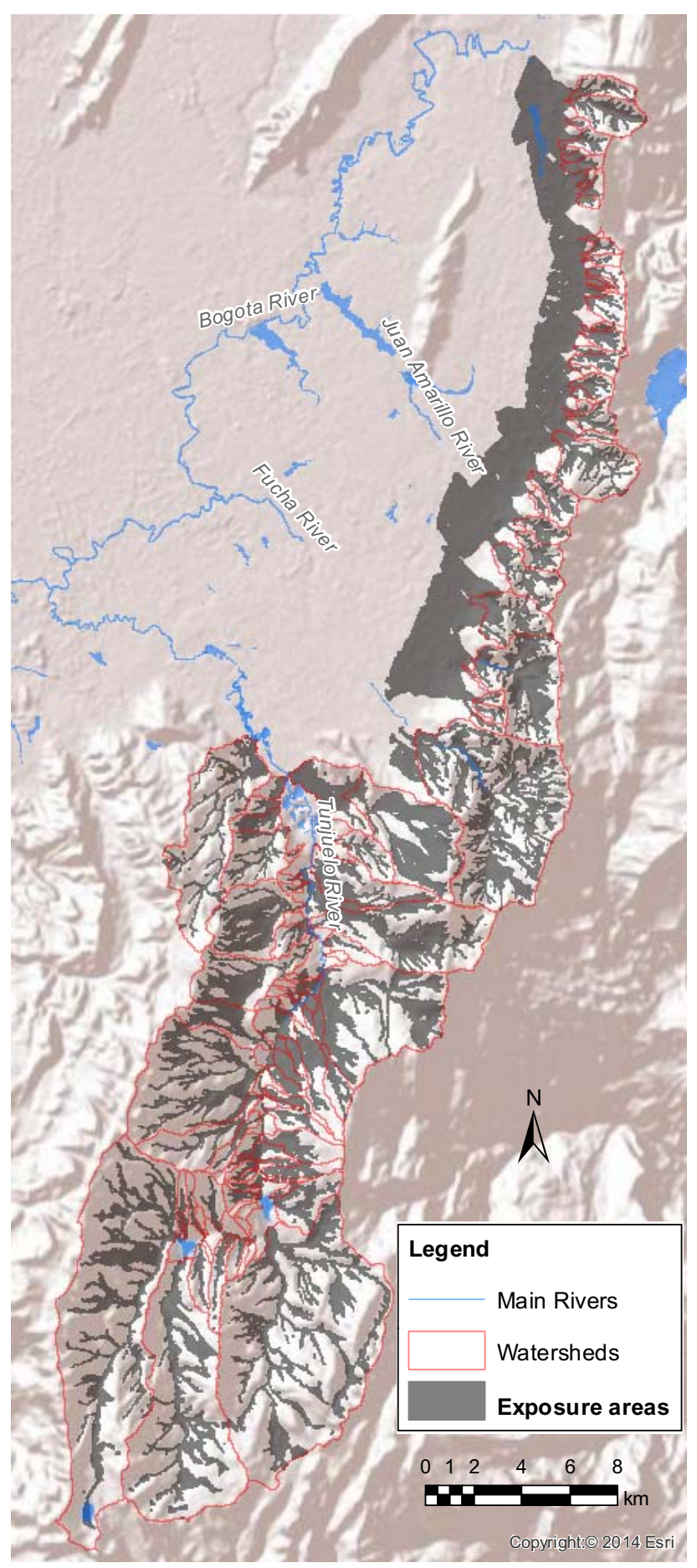

Figure 4. Exposure areas.

a high negative correlation of this variable with lack of education, illiteracy and access to information. This may be due to more institutional effort being allocated to deprived areas that are more often affected by emergency events, in order to strengthen the response capacity of the community. Additionally, civil protection groups rely strongly on voluntary
Table 4. Results of the principal component analysis for socioeconomic fragility indicators.

\begin{tabular}{lcc}
\hline Variable & Symbol & Loadings \\
\hline Lack of well-being $(\mathrm{PVE}=0.8)$ & & \\
\hline Women-headed households & Whh & 0.94 \\
Unemployment & UE & 0.97 \\
Poor-unsatisfied basic needs index & PUBNI & 0.98 \\
$\%$ homeless & Ho & 0.92 \\
\% poor & P & 0.99 \\
Persons per home & Pho & 0.94 \\
Mortality & M & 0.91 \\
Life expectancy & LE & 0.94 \\
Quality life index & QLI & 0.86 \\
Human development index & HDI & 0.97 \\
Population growth rate & G & 0.57 \\
\hline Demography (PVE $=0.2)$ & & \\
\hline$\%$ of children and elderly & Age & 0.84 \\
$\%$ disabled & D & 0.67 \\
$\%$ population strata 1 and 2 & PE12 & 0.81 \\
$\%$ illegal settlements & IS & 0.64 \\
\hline
\end{tabular}

Table 5. Results of the principal component analysis resilience indicators.

\begin{tabular}{lcc}
\hline Variable & Symbol & Loadings \\
\hline Lack of education (PVE= 0.53) & & \\
\hline Level of education & LEd & 0.94 \\
Illiteracy & I & 0.96 \\
Access to information & AI & 0.93 \\
\hline Lack of prep. and resp. & & \\
Capacity (PVE=0.47) & & \\
\hline Infrastructure/accessibility & IA & 0.80 \\
Hospital beds & Hb & 0.97 \\
Healthcare HR & HRh & 0.92 \\
\hline
\end{tabular}

work that seems to be more likely in areas with lower education levels.

Since the consideration of rescue personnel changes the interpretation of the principal component that groups the lack of education and the access to information indicator together, it was decided to exclude it from the PCA and to consider this variable as an independent indicator (lack of rescue capacity).

In the analysis of robberies and participation as variables describing cohesiveness of the community, it was found that the increase in crime is correlated with the lack of participation, describing the distrust of the community both of neighbours and of institutions. The corresponding composite indicator was calculated as the average of robberies and lack of participation. 


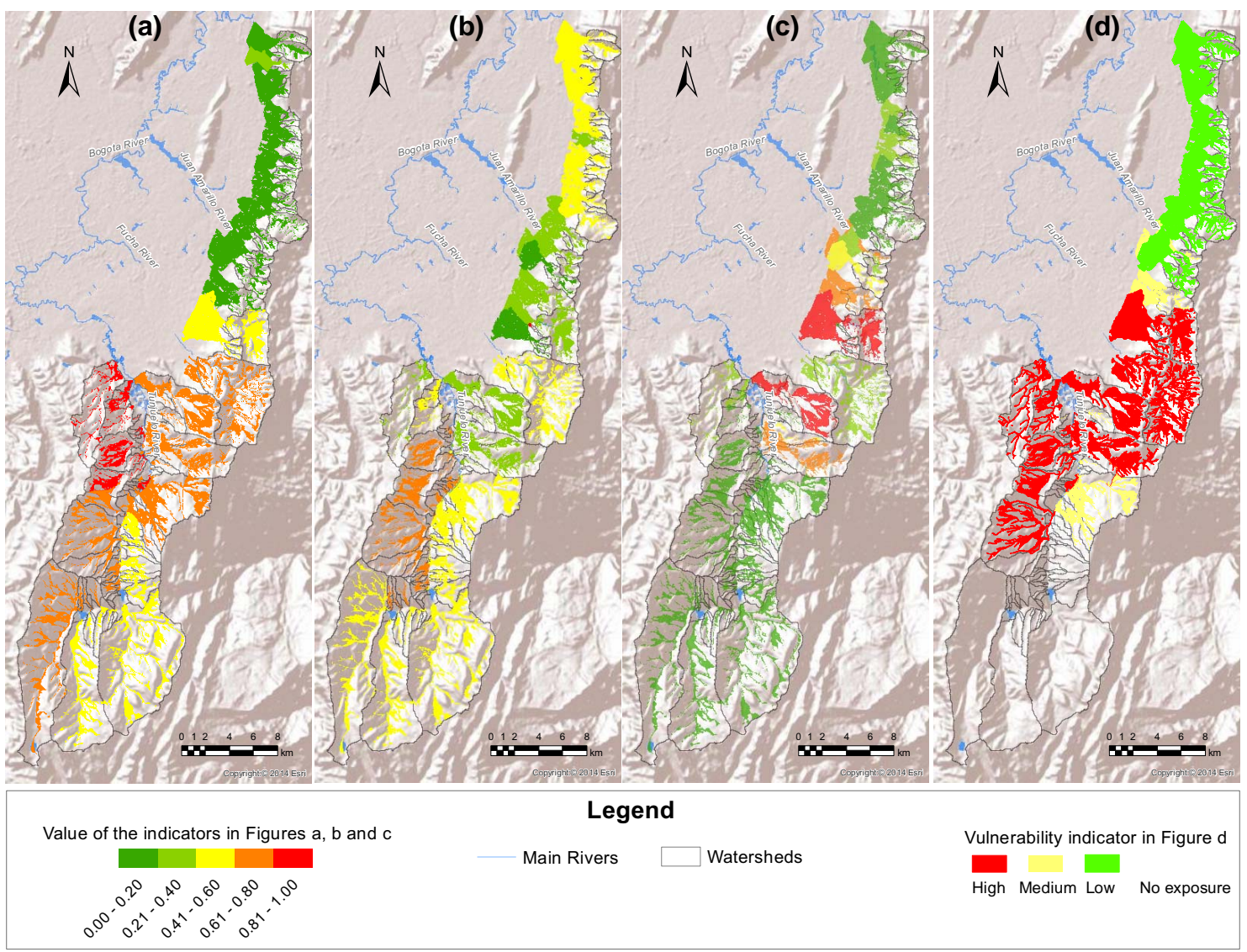

Figure 5. (a) Spatial distribution of the Socio-economic indicator; (b) Spatial distribution of the resilience indicator; (c) spatial distribution of the physical exposure indicator; (d) Spatial distribution of the total vulnerability indicator.

The equation of lack of resilience and coping capacity is shown in Eq. (6). Equal weight was assigned to the indicators reflecting lack of education, lack of preparedness and response capacity, lack of rescue capacity $\left(P_{\mathrm{LRc}}\right)$ and cohesiveness of the community $\left(P_{\mathrm{CC}}\right)$; and a weight of -0.1 to risk perception $\left(P_{\mathrm{RP}}\right)$ and early warning $\left(P_{\mathrm{FEW}}\right)$.

$$
\begin{aligned}
P_{\text {LRes }}= & 0.25 P_{\text {LEdu }}+0.25 P_{\text {LPrRCap }}+0.25 P_{\text {LRc }} \\
& 0.25 P_{\mathrm{CC}}-0.1 P_{\mathrm{RP}}-0.1 P_{\mathrm{FEW}}
\end{aligned}
$$

The indicator of lack of resilience and coping capacity was rescaled between 0 and 1 .

\subsection{Physical exposure indicators}

The principal component analysis of the variables selected for physical exposure shows that these can be grouped into two principal components that explain $82 \%$ of the variability (exposed infrastructure $-P_{\mathrm{Ei}}$ and exposed population $-P_{\mathrm{Ep}}$ ). The results of the analysis are shown in Table 6.
Using the factor loadings obtained from the analysis and scaling them to unity, the coefficients of each composite indicator are shown in the following equations:

$P_{\mathrm{Ei}}=0.32 \mathrm{Ncb}+0.37 \mathrm{Niu}+0.32 \mathrm{Ncu}$

$P_{\text {Ep }}=0.38 \mathrm{Nru}+0.33 \mathrm{Pe}+0.28 \mathrm{Dp}$.

Using the percentage of variability explained (PVE) by each indicator, the composite indicator of physical susceptibility is found to be

$P_{\mathrm{ps}}=0.52 P_{\mathrm{Ei}}+0.48 P_{\mathrm{Ep}}$

\subsection{Vulnerability indicator}

The resulting vulnerability indicator was obtained through the equal-weighted average of the indicators for socioeconomic fragility, lack of resilience and coping capacity and physical exposure. Categories of low, medium and high vulnerability for each watershed were subsequently derived based on equal bins of the indicator value. The spatial distribution is shown in Fig. 5, as well as the spatial distribution of the three constituent indicators. 
Table 6. Results of the principal component analysis physical susceptibility indicators.

\begin{tabular}{lcr}
\hline Variable & Symbol & Loadings \\
\hline Exposed infrastructure (PVE =0.52) & & \\
\hline Number of civic buildings & $\mathrm{Ncb}$ & 0.86 \\
Number of industrial units & $\mathrm{Niu}$ & 0.96 \\
Number of commercial units & $\mathrm{Ncu}$ & 0.85 \\
\hline Exposed population (PVE =0.48) & & \\
\hline Number of residential units & $\mathrm{Nru}$ & 0.91 \\
Population exposed & $\mathrm{Pe}$ & 0.85 \\
Density of population & $\mathrm{Dp}$ & 0.78 \\
\hline
\end{tabular}

\begin{tabular}{|c|c|c|c|c|c|c|c|c|c|}
\hline \multicolumn{5}{|c|}{ (a) Vunerability-susceptibility combination matri } & & \multicolumn{4}{|c|}{ (b) Contingency matrix } \\
\hline \multirow{5}{*}{ 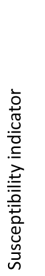 } & & \multicolumn{3}{|c|}{ Vulnerability indicator } & \multirow{5}{*}{ 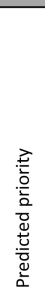 } & & \multicolumn{3}{|c|}{$\begin{array}{l}\text { i. } 3 \times 3 \text { contingency matrix } \\
\text { Observed damage score }\end{array}$} \\
\hline & \multirow[b]{3}{*}{ 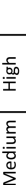 } & High & Medium & Low & & & High & Medium & Low \\
\hline & & High & Medium & Medium & & 点 & 7 & 0 & 0 \\
\hline & & High & Medium & Medium & & $\begin{array}{l}\frac{E}{3} \\
\stackrel{0}{2}\end{array}$ & 0 & 3 & 2 \\
\hline & $\underbrace{3}_{0}$ & Low & Low & Low & & 3 & 0 & 0 & 1 \\
\hline & & & & & & & pportior & orrect $=0.8$ & \\
\hline
\end{tabular}

Figure 6. (a) Vulnerability-susceptibility combination matrix. (b) Contingency matrix.

Conditions of lack of well-being are shown to be concentrated in the south of the study area. The demographic conditions are more variable, showing low values (or better conditions) in the watersheds in the south, where the land use is rural. Low values also occur in the north, where the degree of urbanisation is low due to the more formal urbanisation processes (see Fig. 5a). The spatial distribution of the indicator of lack of resilience and coping capacity (Fig. 5b) shows that the highest values are concentrated in the south-west of the study area where the education levels are lower and the road and health infrastructure are poorer. The same spatial trend is exhibited by the lack of preparedness and response capacity. The area south of the study area corresponds mainly to rural use, thus the physical exposure indicator shows low values (see Fig. 5a). The highest values are concentrated in the centre of the area where the density of population is high and the economic activities are located.

The spatial distribution of the overall indicator and the derived categories show that the high vulnerability watersheds are located in the centre of the study area and in the west.

\subsection{Prioritisation of watersheds according to the qualitative risk indicator and comparison with damage records}

The proportion correct of all possible matrices according to Sect. 3.2.5 (see Fig. 2) resulted in the optimum matrix shown in Fig. 6a, the corresponding contingency matrix is shown in Fig. $6 \mathrm{~b}$ with a proportion correct of 0.85 .

The prioritisation level obtained from the application of the combination matrix to the total vulnerability indicator and the susceptibility indicator for each watershed is shown in Fig. 7a. The results were assigned to the watersheds delineated up to the discharge into the Tunjuelo River or into the storm water system, in order to facilitate the visualisation. The damage categorisation of the study area using the database with historical records according to Table 3 is shown in Fig. $7 \mathrm{~b}$ with range categories classified as high, medium and low. This shows that the most significant damages, corresponding to the highest scores for the impact of flood events, are concentrated in the central zone of the study area. The comparison between Figs. $7 \mathrm{a}$ and $\mathrm{b}$ shows that the indicators identify a similar spatial distribution of priority levels in the central zone of the study area that is consistent with the distribution of recorded damage. This is reflected in the proportion correct of 0.85 .

\subsection{Sensitivity analysis of the vulnerability indicator}

Figure 8 shows the box plots of the values of the vulnerability indicator obtained from the sensitivity analysis in application of PCA as well as the weighting scheme as explained in Sect. 3.2.3. The values of the vulnerability indicator obtained from the proposed method were also plotted for reference. The most influential input factors correspond to the weights used both in the construction of the lack of resilience indicator and in the construction of the total vulnerability indicator. The thick vertical bars for each watershed show the interquartile range of the total vulnerability indicator, with the thin bars showing the range (min-max). While the range of the indicator for some watersheds is substantial, the sensitivity of the watersheds being classified differently in terms of low, medium or high vulnerability was evaluated through the number of watersheds for which the interquartile range intersects with the classification threshold. For seven watersheds classified as being of medium vulnerability, the interquartile range crosses the upper limits of classification of medium vulnerability, while for four watersheds classified as being of high vulnerability, the range crosses that same threshold. For the lower threshold, only two watersheds classified as being of low vulnerability are sensitive to crossing into the class of medium vulnerability. 

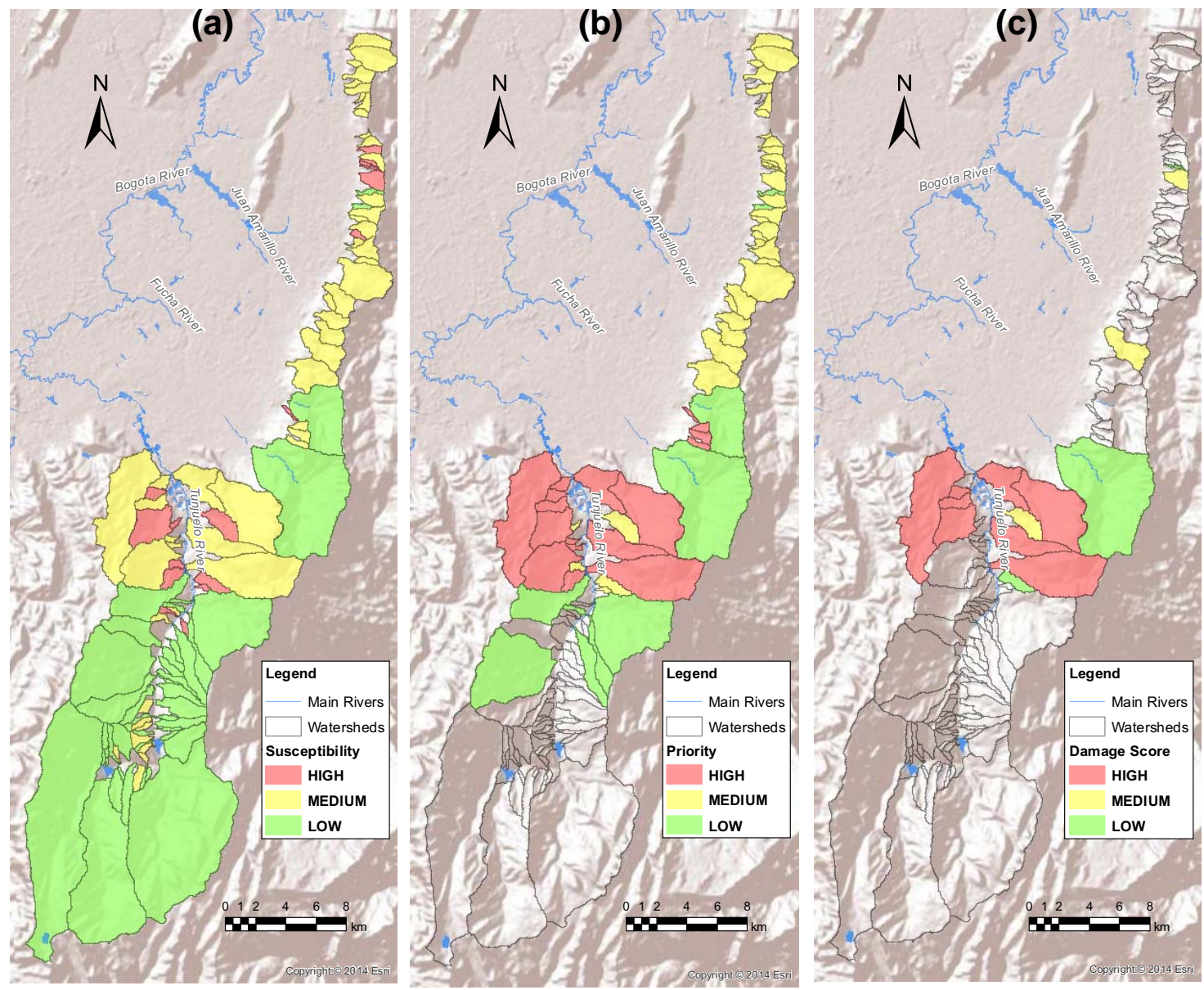

Figure 7. (a) Susceptibility classification of the study area. (b) Prioritisation according to the qualitative risk indicator. (c) Damage categorisation.

\section{Discussion}

\subsection{Exposure areas}

Existing flood hazard maps developed using hydraulic models that were available for a limited set of the watersheds in the study area were used to assess the suitability of the proposed simplified methods to identify flood-prone areas and extend the flood exposure information over the entire study area. The areas exposed to debris flows obtained through the modified single-flow direction propagation algorithm show a good representation of the recorded events (Rogelis and Werner, 2013). However, in the Eastern Hills, where the streams flow towards a flat area, the results of the algorithms tend to overestimate the propagation areas since in these algorithms, the flood extent is dominated purely by the morphology and the flood volume is not considered, which means there is no limitation to the flood extent (see Fig. 4).

Each of the methods applied for flood plain delineation has strengths and weaknesses, while the combination of the results from these methods provides a consistent and conser- vative estimate of the exposure areas. The MRVBF index allows the identification of valley bottoms at several scales. In the mountainous areas, zones contiguous to the streams are identified, and in areas of marked topography the results are satisfactory, allowing a determination of a threshold of the index to define flood-prone areas. In the case of the buffers (see Fig. 4c), a depth of $3 \mathrm{~m}$ seems adequate to represent the general behaviour of the streams. The combination of the methods allowed the estimation of exposure areas based on the morphology (low and flat areas), elevation difference with the stream level (less than $3 \mathrm{~m}$ ) and capacity to propagate debris flows.

\subsection{Representativeness and relative importance of indicators}

The principal component analysis of the variables used to explain socio-economic fragility showed that the 16 variables that were chosen for the analysis could be grouped into two principal components strongly associated with the demography and the lack of well-being in the area. The latter was 


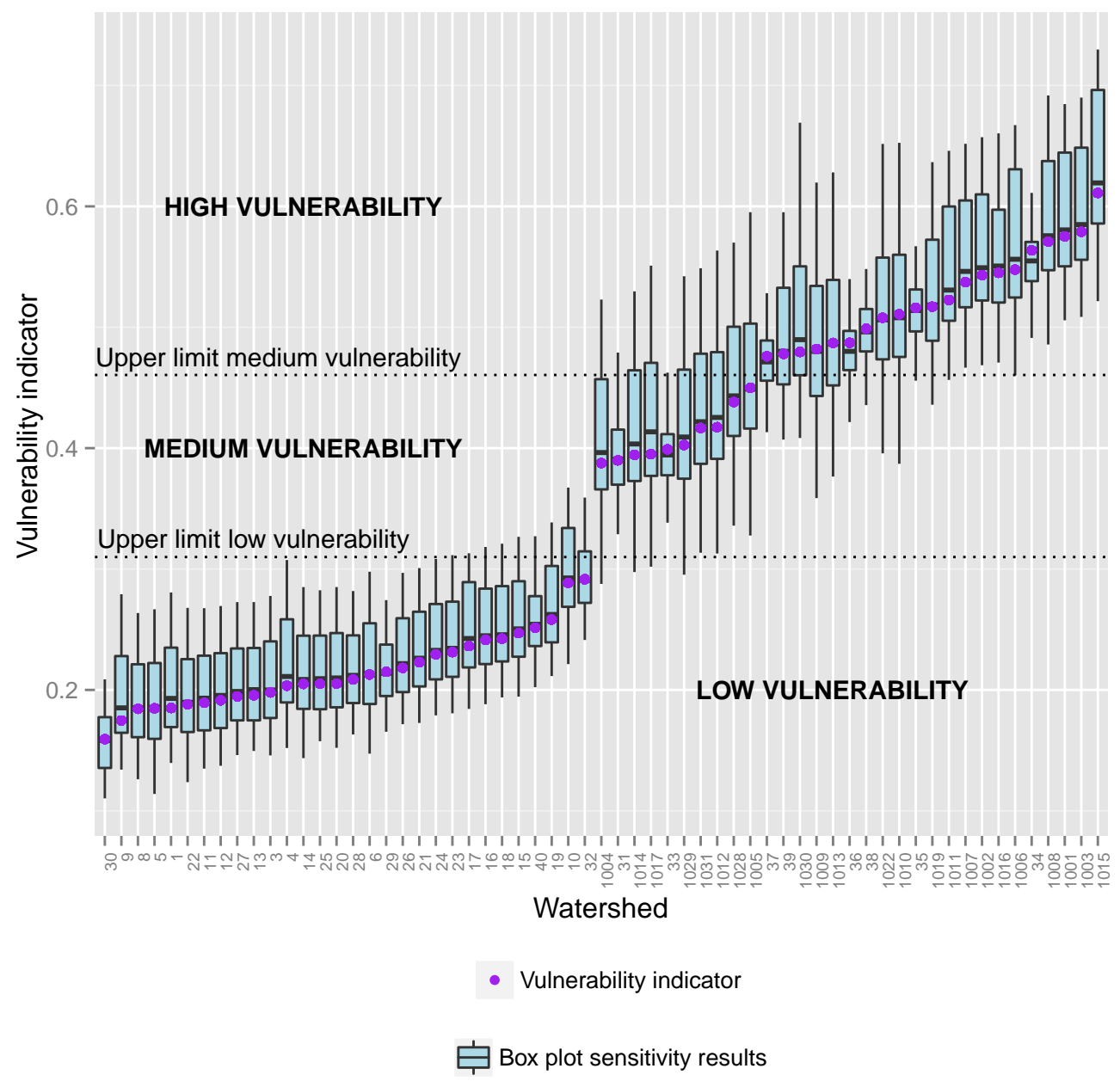

Figure 8. Sensitivity analysis of the vulnerability indicator. Note that the numbering of the watersheds in the Eastern Hills goes from 1 to 40 and in the Tunjuelo River basin from 1000 to 1066.

found to explain most of the variance in the data $(80 \%$ as shown in Table 4).

The demography intermediate indicator describes the dependent population and the origin of the population. Dependent population (children, elderly and disabled) has been also identified by other authors as an important descriptor of vulnerability (Cutter et al., 2003; Fekete, 2009), associated with the limited capacity of this population to evacuate (Koks et al., 2015) and recover (Rygel et al., 2006). The origin of the population (illegal settlements and percentage of population in strata 1 and 2) shows the proportion of population resulting mainly from forced migration due to both violence and poverty (Beltrán, 2008).

The lack of well-being indicator is composed of 14 strongly correlated variables that are commonly used to measure livelihood conditions. Poverty does not necessarily mean vulnerability, though the lack of economic resources is associated with the quality of construction of the houses, health and education, which are factors that influence the capability to face an adverse event (Rygel et al., 2006). The variable "women-headed households" is correlated with the principal component related to lack of well-being as identified by Barrenechea et al. (2000). Even if this condition of the families is not necessarily a criterion related to poverty, women-headed households with children are related to vulnerability conditions. The woman in charge of the family is responsible for the economic, affective and psychological well-being of other persons, especially her children and the elderly, in addition to domestic tasks and the family income. This condition suggests more assistance during emergency and recovery (Barrenechea et al., 2000).

In the case of the lack of resilience and coping capacity indicators, the PCA resulted in the intermediate indicators' lack of education and lack of preparedness and response capacity. The former captures limitations in knowledge about hazards in individuals (Müller et al., 2011) and the latter is linked to the institutional capacity for response. Risk perception and early warning are Boolean indicators. Since risk perception is based on the occurrence or non-occurrence of floods, aspects such as specific knowledge of the population 
about their exposure are not included. In the case of flood early warning, the effectiveness of the systems is not considered. These are aspects that can be taken into account for future research and that can help to improve the lack of resilience and coping capacity indicators.

Regarding the physical exposure, the method that was applied does not involve hazard intensity explicitly and different levels of physical fragility are not considered due to limitations in the available data. The indicators used to express physical exposure imply that the more elements exposed, the more damage, neglecting the variability in the degree of damage that the exposed elements may have. Other regional indicator-based approaches have used physical characteristics of the exposed structures to differentiate levels of damage according to structure type (Kappes et al., 2012) and economic values of the exposed elements (Liu and Lei, 2003). This is a potential area of improvement of the indicator, since the degree of damage depends on the type and intensity of the hazard and the characteristics of the exposed element. However, the development of indicators of physical characteristics and economic values is highly data-demanding, therefore future applications could be aimed at efficiently using existing information and applying innovative data collection methods at a regional level for the improvement of the physical indicators.

\subsection{Sensitivity of the vulnerability indicator}

The interquartile ranges cross the thresholds between categories of low, medium and high vulnerability only in the case of 13 watersheds (see Fig. 8). This means that only these 13 watersheds are sensitive to the criteria selected for the analysis. In 11 of these, the category changes between medium vulnerability and high vulnerability and in the remaining two, the change is from low to medium vulnerability. Watersheds with values of the vulnerability indicator out of the intermediate ranges of the thresholds are robust to the change in the modelling criteria. Clearly, these results are dependent on the number of categories. While introducing more categories may provide more information to differentiate watersheds, the identification of the category of the watersheds may become more difficult due to the sensitivity to the results. Therefore, in order to preserve identifiability of the vulnerability category of the watersheds, no more than three categories could be used. Indicator-based regional studies, which classify vulnerability into three categories, have been shown to provide useful information for flood risk management (Kappes et al., 2012; Liu and Li, 2015; Luino et al., 2012).

The impact on the proportion correct of a shift of category for the 13 watersheds mentioned above can only be assessed for the two watersheds where flood records are available. This does not result in changes in the contingency matrix shown in Fig. 6b. With respect to assigning priority to the watersheds, only 7 (7\% of the total) of the 13 water- sheds that showed sensitivity to a shift of the vulnerability categories were found to be sensitive to a change in priority (high/medium), which reflects the robustness of the analysis using the considered categories.

\subsection{Usefulness of the prioritisation indicator}

The resulting vulnerability-susceptibility combination matrix, shown in Fig. 6a, shows that in the study area, high priorities are determined by high vulnerability conditions and medium and high susceptibility. This would suggest that, high vulnerability is a determinant condition of priority, since areas with high vulnerability can only be assigned a low priority if the susceptibility to flash floods/debris flows is low. This also shows that the analysis of the indicators that compose the vulnerability index allows insight to be gained into the drivers of high vulnerability conditions. Figure 5 shows that high vulnerability watersheds are the result of

- high socio-economic fragility and high lack of resilience and coping capacity (west of the lower and middle basin of the Tunjuelo River; and watershed most to the south of the Eastern Hills);

- high socio-economic fragility and high physical exposure (east of the middle basin of the Tunjuelo River);

- high physical exposure levels (south of the Eastern Hills).

This information is useful for regional allocation of resources for detailed flood risk analysis, with the advantage that the data demand is low in comparison with other indicator-based approaches (Kappes et al., 2012; Fekete, 2009). Furthermore most weights are determined from a statistical analysis with a low influence of subjective weights, which is an advantage over expert weighting, where large variations may occur depending on the expert's perspective (Müller et al., 2011). However, more detailed flood risk management decision-making cannot be informed by the level of resolution used in this study. Studies where assessments are carried out at the level of house units would be needed for planning of mitigation measures, emergency planning and vulnerability reduction (Kappes et al., 2012). Although the proposed procedure could be applied at that more detailed level, this could not be done due to the availability of information. This is a common problem in regional analyses (Kappes et al., 2012) where collecting a large amount of data at high resolution is a challenge. Nevertheless, future advances in collection of data could be incorporated in the proposed procedure, yielding results at finer resolutions. The challenge not only lies in collecting data of good quality at high resolution that can be transformed into indicators, but also in producing data at the same pace as significant changes in variables that contribute to vulnerability take place in the study area. In this research, vulnerability was assessed statically, however, there is an increasing need for analyses that 
take into account the dynamic characteristics of vulnerability (Hufschmidt et al., 2005). Methods such as the one applied in this study can provide a tool to explore these dynamics since it can be adapted to different resolutions according to the data available.

\section{Conclusions}

In this paper a method to identify mountainous watersheds with the highest flood risk at the regional level is proposed. Through this, the watersheds to be subjected to more detailed risk studies can be prioritised in order to establish appropriate flood risk management strategies. The method is demonstrated in the steep, mountainous watersheds that surround the city of Bogotá (Colombia), where floods typically occur as flash floods and debris flows. The prioritisation of the watersheds is obtained through the combination of vulnerability with susceptibility to flash floods/debris flows. The combination is carried out through a matrix that relates levels of vulnerability and susceptibility with priority levels.

The analysis shows the interactions between drivers of vulnerability, and how the understanding of these drivers can be used to gain insight into the conditions that determine vulnerability to floods in mountainous watersheds. Vulnerability is expressed in terms of composite indicators: socio-economic fragility, lack of resilience and coping capacity and physical exposure. Each of these composite indicators is formed by an underlying set of constituent indicators that reflect the behaviour of highly correlated variables, and that represent characteristics of the exposed elements. The combination of these three component indicators allowed the calculation of a vulnerability indicator, from which a classification into high, medium and low vulnerability was obtained for the watersheds of the study area. Tracing back the composite indicators that generate high vulnerability provided an understanding of the conditions of watersheds that are more critical, allowing these to be targeted for more detailed flood risk studies. In the study area it is shown that those watersheds with high vulnerability are categorised to be of high priority, unless the susceptibility is low, indicating that the vulnerability is the main contributor to risk. Furthermore, the contributing components that determine high vulnerability could be identified spatially in the study area.

The developed methodology can be applied to other areas, although adaptation of the variables considered may be required depending on the setting and the available data. The proposed method is flexible to the availability of data, which is an advantage for assessments in mountainous developing cities and when the evolution in time of variables that contribute to vulnerability is taken into account.

The results also demonstrate the need for a comprehensive documentation of damage records, as well as the potential for improvement of the method. Accordingly, further research should be focused on (i) the use of smaller units of analysis than the watershed scale, which was used in this study; (ii) improvement of physical exposure indicators, incorporating type of structures and economic loss; and (iii) incorporation of more detailed information about risk perception and flood early warning.

Acknowledgements. This work was funded by the UNESCO-IHE Partnership Research Fund - UPaRF - in the framework of the FORESEE project. We wish to express our gratitude to the Fondo de Prevención y Atención de Emergencias de Bogotá for providing the flood event data for this analysis. We also would like to thank Sven Fuchs and another anonymous reviewer, whose comments helped improve and clarify this paper.

Edited by: H. Kreibich

Reviewed by: S. Fuchs and one anonymous referee

\section{References}

Akbas, S., Blahut, J., and Sterlacchini, S.: Critical assessment of existing physical vulnerability estimation approaches for debris flows, in: Landslide processes: from geomorphological mapping to dynamic modelling, 229-233, 2009.

Albano, R., Sole, A., Adamowski, J., and Mancusi, L.: A GIS-based model to estimate flood consequences and the degree of accessibility and operability of strategic emergency response structures in urban areas, Nat. Hazards Earth Syst. Sci., 14, 2847-2865, doi:10.5194/nhess-14-2847-2014, 2014.

Balica, S. F., Wright, N. G., and van der Meulen, F.: A flood vulnerability index for coastal cities and its use in assessing climate change impacts, Nat. Hazards, 64, 73-105, doi:10.1007/s11069012-0234-1, 2012.

Barrenechea, J., Gentile, E., González, S., and Natenson, C.: Una propuesta metodológica para el estudio de la vulnerabilidad social en el marco de la teoría social del riesgo, in: IV Jornadas de Sociología, edited by: Facultad de Ciencias Sociales Facultad de Ciencias Sociales, UBA, Buenos Aires, Argentina, 1-13, 2000.

Barroca, B., Bernardara, P., Mouchel, J. M., and Hubert, G.: Indicators for identification of urban flooding vulnerability, Nat. Hazards Earth Syst. Sci., 6, 553-561, doi:10.5194/nhess-6-5532006, 2006.

Beltrán, J.: Crecimiento Urbano, Pobreza y Medio Ambiente en Bogotá: Los Efectors Soci Ambientales en Tres Humedales, in: CII Seminario Nacional de Investigación Urbano Regional, Medellín, Colombia, 1-13, 2008.

Bernal, G., Rosero, M., Cadena, M., Montealegre, J., and Sanabria, F.: Estudio de la Caracterización Climática de Bogotá y cuenca alta del Río Tunjuelo, Tech. rep., Instituto de Hidrología, Meteorología y Estudios Ambientales IDEAM - Fondo de Prevención y Atención de Emergencias FOPAE, Bogotá, Colombia, 2007.

Birkmann, J.: Measuring vulnerability to natural hazards: toward disaster resilient societies, second edn., edited by: Birkmann, J., United Nations University Press, New York, USA, 460 pp., 2006.

Birkmann, J., Cardona, O. D., Carreño, M. L., Barbat, A. H., Pelling, M., Schneiderbauer, S., Kienberger, S., Keiler, M., Alexander, D., Zeil, P., and Welle, T.: Framing vulnerability, risk and societal responses: the MOVE framework, Nat. Hazards, 67, 193-211, 2013. 
Birkmann, J., Cardona, O. D., Carreño, M. L., Barbat, A. H., Pelling, M., Schneiderbauer, S., Zeil, P., and Welle, T.: Theoretical and Conceptual Framework for the Assessment of Vulnerability to Natural Hazards and Climate Change in Europe, in: Assessment of Vulnerability to Natural Hazards: A European Perspective, edited by: Birkmann, J., Kienberger, S., and Alexander, D., Elsevier, San Diego, California, USA, chap. 1, 1-19, 2014.

Buendía, J. A. T.: Relaciones socioespaciales en los Cerros Orientales: prácticas, valores y formas de apropiación territorial en torno a las quebradas la Vieja y las Delicias en Bogotá, PhD thesis, Universidad Colegio Mayor Nuestra Señora del Rosario, Bogotá, Colombia, 2013.

Cardona, O.: The need for rethinking the concepts of vulnerability and risk from a holistic perspective: a necessary review and criticism for effective risk management, in: Mapping Vulnerability: Disasters, Development and People, edited by: Bankoff, G., Frerks, G., and Hilhorst, D., chap. 3, Earthscan Publishers, London, UK, 37-51, 2003.

Cardona, O. D.: Estimación Holística del Riesgo Sísmico utilizando Sistemas Dinámicos Complejos, PhD thesis, Universidad Politécnica de Cataluña, Barcelona, Spain, 2001.

Cardona, O. D., Van Aalts, M. K., Birkmann, J., Fordham, M., Glenn, M., Perez, R., Pulwarty, R. S., Schipper, L. F., and Sinh, B. T.: Determinants of Risk : Exposure and Vulnerability, in: Managing the Risks of Extreme Events and Disasters to Advance Climate Change Adaptation. A Special Report of Working Groups I and II of the Intergovernmental Panel on Climate Change (IPCC), Cambridge University Press, Cambridge, UK, and New York, NY, USA, chap. Determinan, 65-108, 2012.

Carroll, J.: An analytical solution for approximating simple structure in factor analysis, Psychometrika, 18, 23-38, doi:10.1007/BF02289025, 1953.

Carroll, J.: Biquartimin criterion for rotation to oblique simple structure in factor analysis, Science, 126, 1114-1115, doi:10.1126/science.126.3283.1114, 1957.

Cattell, R.: The scree test for the number of factors, Multivar. Behav. Res., 1, 245-276, doi:10.1207/s15327906mbr0102_10, 1966.

Chen, Y., Barrett, D., Liu, R., and Gao, L.: A spatial framework for regional-scale flooding risk assessment, 7th International Congress on Environmental Modelling and Software, 15-19 June 2014, San Diego, CA, USA, 2014.

Cimmery, B. V.: User Guide for SAGA (version 2.0.5), 2, 2010.

Costa, J.: Rheologic, geomorphic, and sedimentologic differentiation of water floods, hyperconcentrated flows, and debris flows, in: Flood Geomorphology, edited by: Baker, V. R., Kochel, R. C., and Patton, P. C., Wiley, New York, USA, 113-122, 1988.

Cutter, S., Boruff, B., and Shirley, W.: Social vulnerability to environmental hazards, Soc. Sci. Quart., 84, 242-261, doi:10.1111/1540-6237.8402002, 2003.

Cutter, S. L., Barnes, L., Berry, M., Burton, C., Evans, E., Tate, E., and Webb, J.: A place-based model for understanding community resilience to natural disasters, Global Environ. Chang., 18, 598-606, 2008.

DPAE: Diagnóstico Técnico 1836, Tech. rep., Direccion de Prevención y Atención de Emergencias de Bogotá, Bogotá, Colombia, 2003a.

DPAE: Diagnóstico Técnico 1891, Tech. rep., Direccion de Prevención y Atención de Emergencias de Bogotá, Bogotá, Colombia, $2003 b$.
DPAE: Diagnóstico Técnico 2414, Tech. rep., Direccion de Prevención y Atención de Emergencias de Bogotá, Bogotá, Colombia, 2005.

Esty, D., Srebotnjak, T., Kim, C., Levy, M., Sherbinin, A., and Anderson, B.: Pilot 2006 Environmental Performance Index, Tech. rep., Yale Center for Environmental Law \& Policy, New Haven, USA, 2006.

Fekete, A.: Validation of a social vulnerability index in context to river-floods in Germany, Nat. Hazards Earth Syst. Sci., 9, 393 403, doi:10.5194/nhess-9-393-2009, 2009.

Fuchs, S.: Susceptibility versus resilience to mountain hazards in Austria - paradigms of vulnerability revisited, Nat. Hazards Earth Syst. Sci., 9, 337-352, doi:10.5194/nhess-9-337-2009, 2009.

Fuchs, S. and Holub, M.: Reducing Physical Vulnerability to Mountain Hazards, in: 12th Congress INTERPRAEVENT 2012 , Grenoble, France, 675-686, 2012.

Fuchs, S., Heiss, K., and Hübl, J.: Towards an empirical vulnerability function for use in debris flow risk assessment, Nat. Hazards Earth Syst. Sci., 7, 495-506, doi:10.5194/nhess-7-4952007, 2007.

Fuchs, S., Tsao, T.-C., and Keiler, M.: Quantitative Vulnerability Functions for use in Mountain Hazard Risk Management in: 12th Congress INTERPRAEVENT 2012, Grenoble, France, 885-896, 2012.

Gallant, J. and Dowling, T.: A multiresolution index of valley bottom flatness for mapping depositional areas, Water Resour. Res., 39, 1347-1360, 2003.

Greiving, S.: Multi-risk assessment of Europe's regions, Measuring Vulnerability to Natural Hazards: Toward Disaster Resilient Societies, United Nations University, New York, USA, 2006.

Harris, C. and Kaiser, H.: Oblique factor analytic solutions by orthogonal transformations, Psychometrika, 29, 347-362, doi:10.1007/BF02289601, 1964.

Hendrickson, A. and White, P.: Promax: A quick method for rotation to oblique simple structure, Brit. J. Statist. Psych., 1964.

Holub, M., Suda, J., and Fuchs, S.: Mountain hazards: Reducing vulnerability by adapted building design, Environ. Earth Sci., 66, 1853-1870, 2012.

Horn, J.: A rationale and test for the number of factors in factor analysis, Psychometrika, 30, 179-185, doi:10.1007/BF02289447, 1965.

Hu, K. H., Cui, P., and Zhang, J. Q.: Characteristics of damage to buildings by debris flows on 7 August 2010 in Zhouqu, Western China, Nat. Hazards Earth Syst. Sci., 12, 2209-2217, doi:10.5194/nhess-12-2209-2012, 2012.

Hufschmidt, G., Crozier, M., and Glade, T.: Evolution of natural risk: research framework and perspectives, Nat. Hazards Earth Syst. Sci., 5, 375-387, doi:10.5194/nhess-5-375-2005, 2005.

Hyndman, D. W. and Hyndman, D. W.: Natural hazards and disasters, Yolanda Cossio, Belmont, USA, 4 edn., 2008.

IWR: Flood Risk Management Approaches. As being practiced in Japan, the Netherlands, United Kingdom and United States, United States Army Corps of Engineers, Washington, DC, USA, 2011.

Jakob, M.: Debris-flow hazard analysis, in: Debris-flow hazards and related phenomena, edited by: Jakob, M. and Hungr, O., Springer-Verlag, Berlin, Germany, chap. 17, 411-443, 2005. 
Jakob, M., Porter, M., Savigny, K. W., and Yaremko, E.: A geomorphic approach to the design of pipeline crossings of mountain streams, Proceedings of IPC 2004: International Pipeline Conference, 4-8 October 2004, Calgary, Alberta, Canada, 1-8, 2004.

Jakob, M., Stein, D., and Ulmi, M.: Vulnerability of buildings to debris flow impact, Nat. Hazards, 60, 241-261, 2012.

Jakob, M., Holm, K., Weatherly, H., Liu, S., and Ripley, N.: Debris flood risk assessment for Mosquito Creek, British Columbia, Canada, Natural Hazards, 65, 1653-1681, http://link.springer. com/10.1007/s11069-012-0436-6, 2013.

Jha, A., Bloch, R., and Lamond, J.: Cities and Flooding A guide to Integrated Urban Flood Risk Management for the 21st Century, The World Bank Location: Washington, DC, USA, 2012.

JICA: Study on monitoring and early warning systems for landslide and floods in Bogotá and Soacha, Tech. rep., Japanese Internation Cooperation Agency - JICA, Bogotá, Colombia, 2006.

Jolliffe, I. T.: Principal Component Analysis, Springer Series in Statistics, Springer-Verlag, New York, USA, 2002.

Jonkman, S., Bočkarjova, M., Kok, M., and Bernardini, P.: Integrated hydrodynamic and economic modelling of flood damage in the Netherlands, Ecol. Econ., 66, 77-90, 2008.

Kaiser, H.: The varimax criterion for analytic rotation in factor analysis, Psychometrika, 23, 187-200, doi:10.1007/BF02289233,1958.

Kaiser, H.: The application of electronic computers to factor analysis., Educ. Psychol. Meas., 20, 141-151, doi:10.1177/001316446002000116, 1960.

Kappes, M., Papathoma-Köhle, M., and Keiler, M.: Assessing physical vulnerability for multi-hazards using an indicator-based methodology, Appl. Geogr., 32, 577-590, http://linkinghub. elsevier.com/retrieve/pii/S0143622811001378, 2012.

Kiers, H.: SIMPLIMAX: Oblique rotation to an optimal target with simple structure, Psychometrika, 59, 567-579, doi:10.1007/BF02294392, 1994.

Koks, E., Jongman, B., Husby, T., and Botzen, W.: Combining hazard, exposure and social vulnerability to provide lessons for flood risk management, Environ. Sci. Pol., 47, 42-52, http:// linkinghub.elsevier.com/retrieve/pii/S1462901114002056, 2015.

Larsen, M., Wieczorek, G., Eaton, L., and Torres-Sierra, H.: Natural Hazards on Aluvial Fans: The Debris Flow and Flash flood disaster of December 1999, Vargas State, Venezuela, in: Proceedings of the Sixth Caribbean Islands Water Resources Congress, edited by: Sylva, W., Mayagüez, Puerto Rico, 00965, 1-7, 2001.

Lavigne, F. and Suwa, H.: Contrasts between debris flows, hyperconcentrated flows and stream flows at a channel of Mount Semeru, East Java, Indonesia, Geomorphology, 61, 41-58, 2004.

Liu, D. L. and Li, Y.: Social vulnerability of rural households to flood hazards in western mountainous regions of Henan province, China, Nat. Hazards Earth Syst. Sci. Discuss., 3, 67276744, doi:10.5194/nhessd-3-6727-2015, 2015.

Liu, X. and Lei, J.: A method for assessing regional debris flow risk: an application in Zhaotong of Yunnan province (SW China), Geomorphology, 52, 181-191, http://linkinghub.elsevier. com/retrieve/pii/S0169555X02002428, 2003.

Liu, Y., Zhou, J., Song, L., Zou, Q., Guo, J., and Wang, Y.: Efficient GIS-based model-driven method for flood risk management and its application in central China, Nat. Hazards Earth Syst. Sci., 14, 331-346, doi:10.5194/nhess-14-331-2014, 2014.
Lo, W.-C., Tsao, T.-C., and Hsu, C.-H.: Building vulnerability to debris flows in Taiwan: a preliminary study, Nat. Hazards, 64, 2107-2128, http://www.springerlink.com/index/10. 1007/s11069-012-0124-6, 2012.

Luino, F., Cirio, C. G., Biddoccu, M., Agangi, A., Giulietto, W., Godone, F., and Nigrelli, G.: Application of a model to the evaluation of flood damage, Geoinformatica, 13, 339-353, 2009.

Luino, F., Turconi, L., Petrea, C., and Nigrelli, G.: Uncorrected land-use planning highlighted by flooding: the Alba case study (Piedmont, Italy), Nat. Hazards Earth Syst. Sci., 12, 2329-2346, doi:10.5194/nhess-12-2329-2012, 2012.

Luna, B., Blahut, J., Kappes, M., Akbas, S. O., Malet, J. P., Remaître, A., and Jaboyedoff, M.: Methods for Debris Flow Hazard and Risk Assessment, in: Mountain Risks: From Prediction to Management and Governance, pp. 133-177, http://www. springer.com/us/book/9789400767683, 2014.

Mazzorana, B., Levaggi, L., Keiler, M., and Fuchs, S.: Towards dynamics in flood risk assessment, Nat. Hazards Earth Syst. Sci., 12, 3571-3587, doi:10.5194/nhess-12-3571-2012, 2012.

Molinari, D., Molini, S., and Ballio, F.: Flood Early Warning Systems: Knowledge and Tools for Their Critical Assessment, WIT Press, Southampton, UK, 2013.

Müller, A., Reiter, J., and Weiland, U.: Assessment of urban vulnerability towards floods using an indicator-based approach - a case study for Santiago de Chile, Nat. Hazards Earth Syst. Sci., 11, 2107-2123, doi:10.5194/nhess-11-2107-2011, 2011.

Nardi, F., Vivoni, E. R., and Grimaldi, S.: Investigating a floodplain scaling relation using a hydrogeomorphic delineation method, Water Resour. Res., 42, 1-15, 2006.

Nardo, M., Saisana, M., Saltelli, A., Tarantola, S., Hoffman, A., and Giovannini, E.: Handbook on Constructing Composite Indicators, OECD publishing, Ispra, Italy, 2008.

Neuhaus, J. O.: The Quartimax Method: An Analytic Approach to Orthogonal Simple Structure, Brit. J. Statist. Psych., 7, 81-91, 1954.

Nkwunonwo, U., Whitworth, M., and Baily, B.: Relevance of Social Vulnerability Assessment to Flood Risk Reduction in the Lagos Metropolis of Nigeria, British Journal of Applied Science \& Technology, 8, 366-382, http://www.sciencedomain.org/ abstract.php?iid=1072\&id=5\&aid=8949, 2015.

Osorio, J. A.: El río Tunjuelo en la historia de Bogotá, 1900-1990, Alcaldia Mayor de Bogotá, Bogotá, Colombia, 2007.

Pacific Disaster Center: Bogotá, Colombia Disaster Risk Management Profile, 3CD City Profiles Series, Bogotá, Colombia, 2006.

Papathoma-Köhle, M., Kappes, M., Keiler, M., and Glade, T.: Physical vulnerability assessment for alpine hazards: state of the art and future needs, Nat. hazards, 58, 645-680, http://link.springer. com/10.1007/s11069-010-9632-4, 2011.

Papathoma-Köhle, M., Keiler, M., Totschnig, R., and Glade, T.: Improvement of vulnerability curves using data from extreme events: debris flow event in South Tyrol, Natural Hazards, 64, 2083-2105, http://link.springer.com/10.1007/ s11069-012-0105-9, 2012.

Quan Luna, B., Blahut, J., van Westen, C. J., Sterlacchini, S., van Asch, T. W. J., and Akbas, S. O.: The application of numerical debris flow modelling for the generation of physical vulnerability curves, Nat. Hazards Earth Syst. Sci., 11, 2047-2060, doi:10.5194/nhess-11-2047-2011, 2011. 
Rogelis, M. C. and Werner, M.: Regional debris flow susceptibility analysis in mountainous peri-urban areas through morphometric and land cover indicators, Nat. Hazards Earth Syst. Sci., 14, 3043-3064, doi:10.5194/nhess-14-3043-2014, 2014.

Ruiz-Pérez, M. and Gelabert Grimalt, M.: Análisis De La Vulnerabilidad Social Frente a Desastres Naturales: El Caso De La Isla De Mallorca, GeoSig, 4, 1-26, 2012.

Rygel, L., O'sullivan, D., and Yarnal, B.: A method for constructing a social vulnerability index: an application to hurricane storm surges in a developed country, Mitigation and Adaptation Strategies for Global Change, 11, 741-764, doi:10.1007/s11027-0060265-6, 2006.

Safaripour, M., Monavari, M., and Zare, M.: Flood risk assessment using GIS (case study: Golestan province, Iran), Pol. J. Environ. Stud., 21, 1817-1824, 2012.

Santo, A., Santangelo, N., Di Crescenzo, G., Scorpio, V., De Falco, M., and Chirico, G. B.: Flash flood occurrence and magnitude assessment in an alluvial fan context: the October 2011 event in the Southern Apennines, Nat. Hazards, http://link.springer.com/ 10.1007/s11069-015-1728-4, 2015.

Schanze, J., Zeman, E., and Marsalek, J.: Flood risk management: hazards, vulnerability and mitigation measures, Springer, Dordrecht, the Netherlands, 2006.

Schmidtlein, M. C., Deutsch, R., Piegorsch, W. W., and Cutter, S. L.: Building indexes of Vulnerability : a sensitivity analysis of the Social Vulnerability Index, Risk Anal., 28, 1099-1114, 2008.

Seethapathi, P., Dutta, D., and Kumar, R.: Hydrology of small watersheds, The Energy and Resources Institute, New Deli, India, 2008.

Seifert, I., Thieken, A. H., Merz, M., Borst, D., and Werner, U.: Estimation of industrial and commercial asset values for hazard risk assessment, Nat. Hazards, 52, 453-479, 2009.

Sterlacchini, S., Akbas, S. O., Blahut, J., Mavrouli, O.-C., Garcia, C., Luna, B. Q., and Corominas Dulcet, J.: Methods for the characterization of the vulnerability of elements at risk, in: Mountain risks: from prediction to management and governance, Springer Netherlands, Dordrecht, the Netherlands, 33-273, http: //hdl.handle.net/2117/20764, 2014.

Su, M. and Kang, J.: A grid-based GIS approach to regional flood damage assessment, J. Mar. Sci. Technol., 13, 184-192, 2005.
Thieken, A., Merz, B., Kreibich, H., and Apel, H.: Methods for flood risk assessment: Concepts and challenges, International Workshop on Flash Floods in Urban Areas Muscat, 4-6 September 2006, Oman, 1-12 2006.

Totschnig, R. and Fuchs, S.: Mountain torrents: Quantifying vulnerability and assessing uncertainties, Eng. Geol., 155, 31-44, doi:10.1016/j.enggeo.2012.12.019, 2013.

Totschnig, R., Sedlacek, W., and Fuchs, S.: A quantitative vulnerability function for fluvial sediment transport, Nat. Hazards, 58, 681-703, http://link.springer.com/10.1007/s11069-010-9623-5, 2011.

Tsao, T.-C., Hsu, W.-K., Cheng, C.-T., Lo, W.-C., and Chen, C.Y.: A preliminary study of debris flow risk estimation and management in Taiwan, International symposium interpraevent in the Pacific Rim, 26-30 April 2010, Taipei, 930-939, 2010.

UNEP: Assessing Human Vulnerability to Environmental Change: Concepts, Issues, Methods and Case Studies, Nairobi, Kenya, 57 pp., 2003.

UNISDR: Living with risk: a global review of disaster reduction initiatives, vol. 1, 2004.

UNISDR: Terminology on Disaster Risk Reduction, Tech. rep., United Nations International Strategy for Disaster Reduction, Geneva, Switzerland, 2009.

United Nations General Assembly: Resolution adopted by the General Assembly on 3 June 2015, Sendai Framework for Disaster Risk Reduction 2015-2030, 08955, 1-24, http://www. preventionweb.net/files/resolutions/N1516716.pdf, 2015.

van Westen, C., Kappes, M., Luna, B., Frigerio, S., Glade, T., and Malet, J.-P.: Medium-Scale Multi-hazard Risk Assessment of Gravitational Processes, in: Mountain Risks: From Prediction to Management and Governance SE - 7, 34, 201-231, http://dx.doi.org/10.1007/978-94-007-6769-0_7, 2014.

Varnes, D. J.: Landslide hazard zonation: a review of principles and practice, Tech. rep., Commission on landslides of the IAEG, UNESCO, 1984.

Wisner, B., Blaikie, P., and Cannon, T.: At Risk: natural hazards, people's vulnerability and disasters, Routledge, second edn., 2003. 